\title{
Acyl(imidoyl)ketenes: Reactive Bidentate Oxa/Aza-Dienes for Organic Synthesis
}

\author{
Ekaterina A. Lystsova (D), Ekaterina E. Khramtsova *(D) and Andrey N. Maslivets * \\ Department of Chemistry, Perm State University, ul. Bukireva, 15, 614990 Perm, Russia; liscova_ea@mail.ru \\ * Correspondence: caterina.stepanova@psu.ru (E.E.K.); koh2@psu.ru (A.N.M.)
}

\begin{abstract}
Polyfunctional building blocks are essential for the implementation of diversity-oriented synthetic strategies, highly demanded in small molecule libraries' design for modern drug discovery. Acyl(imidoyl)ketenes are highly reactive organic compounds, bearing both oxa- and aza-diene moieties, conjugated symmetrically to the ketene fragment, enabling synthesis of various skeletally diverse heterocycles on their basis. The highlights of reactions utilizing acyl(imidoyl)ketenes are high yields, short reaction time (about several minutes), high selectivity, atom economy, and simple purification procedures, which benefits the drug discovery. The present review focuses on the approaches to thermal generation of acyl(imidoyl)ketenes, patterns of their immediate transformations via intraand intermolecular reactions, including the reactions of cyclodimerization, in which either symmetric or dissymmetric heterocycles can be formed. Recent advances in investigations on mechanisms, identifications of intermediates, and chemo- and regioselectivity of reactions with participation of acyl(imidoyl)ketenes are also covered.
\end{abstract}

Keywords: acyl(imidoyl)ketene; aza-diene; cycloaddition; decarbonylation; dienophile; diversityoriented synthesis; heterocumulene; oxa-diene; thermolysis; zwitterion

Citation: Lystsova, E.A.

Khramtsova, E.E.; Maslivets, A.N.

Acyl(imidoyl)ketenes: Reactive

Bidentate Oxa/Aza-Dienes for

Organic Synthesis. Symmetry 2021, 13,

1509. https://doi.org/10.3390/

sym13081509

Academic Editor: Radomir Jasiński

Received: 27 July 2021

Accepted: 16 August 2021

Published: 17 August 2021

Publisher's Note: MDPI stays neutral with regard to jurisdictional claims in published maps and institutional affiliations.

\section{Introduction}

Recently, diversity-oriented synthesis (DOS), a technique for transforming a group of simple and similar starting materials into a collection of more complex and diverse products [1], has become an important trend in drug discovery [1-9]. DOS allows us to explore wider chemistry space, including currently deficiently presented (or even vacant) space and, in perspective, space correlating best with needed properties [1]. Implementation of DOS requires available polyfunctional building blocks with studied chemical properties to predict and tune their chemical behavior in the developing strategy. Acyl(imidoyl)ketenes A are well suited to these requirements, as these molecules bear a forked diene fragment consisting of a $\mathrm{C}=\mathrm{C}$ bond conjugated with geminal $\mathrm{C}=\mathrm{O}$ and $\mathrm{C}=\mathrm{N}$ patterns, which enables the development of DOS based on them with an emphasis on skeletal diversity (Scheme 1). Moreover, immediate reactions of some types of acyl(imidoyl)ketenes A afford the formation of symmetric products, which could possibly increase the likelihood of the occurrence of useful biological properties in them [10,11].

Acyl(imidoyl)ketenes $\mathbf{A}$ are compounds bearing oxa- and aza-diene reaction centers symmetrically located relative to the heterocumulene (ketene) fragment (Scheme 1), which makes them similar both to acyl- and imidoylketenes, well-studied building blocks widely used in organic synthesis [12-37]. Therefore, chemical transformations of such hybrid structures as acyl(imidoyl)ketenes $\mathbf{A}$ can involve both oxa- and aza-diene fragments.

Acyl(imidoyl)ketenes A belong to the category of highly reactive compounds. Most often, they are generated in the result of the elimination of carbon monoxide (CO) from monocyclic 4-acyl-1H-pyrrole-2,3-diones 1 or their [e]-fused analogs 2 under thermolysis conditions at temperatures above $110{ }^{\circ} \mathrm{C}$ (Scheme 2) [36-40]. Another approach to acyl(imidoyl)ketenes $\mathbf{A}$ is based on the thermolysis of (quinoxalin-2-yl)furan-2,3-diones 3 
(Scheme 2) [41]. Moreover, generation of acyl(imidoyl)ketenes A is possible in the course of Gould-Jacobs reaction via the thermolysis of 2-(aminomethylene)malonates 4 [42,43].

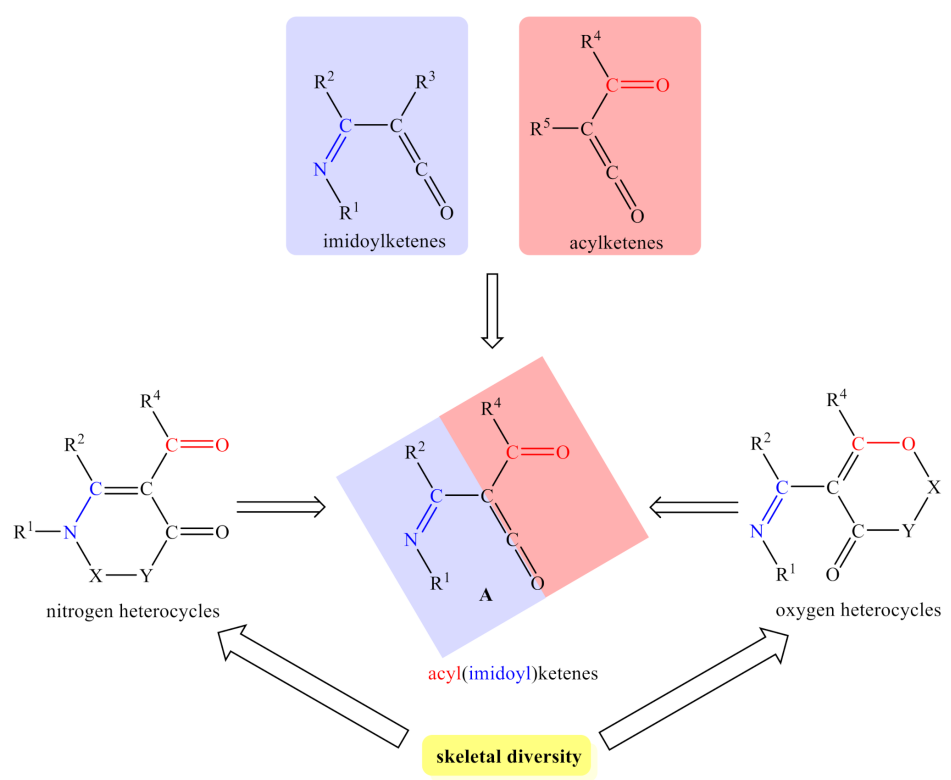

Scheme 1. Acyl(imidoyl)ketenes A and some of their DOS possibilities.

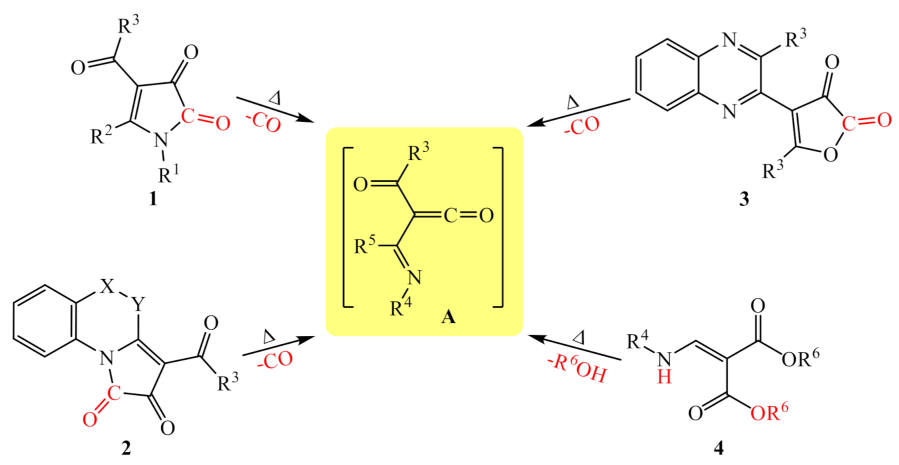

Scheme 2. Approaches to generation of acyl(imidoyl)ketenes A.

Although acyl(imidoyl)ketenes A are highly reactive, and their isolation seems to be extremely difficult, their formation was instrumentally proven by flash vacuum thermolysis (FVT) studies of 4-acyl-1H-pyrrole-2,3-diones $\mathbf{1}[37,39,40,44,45]$. In these experiments, the examined compounds were heated to temperatures of $500-700{ }^{\circ} \mathrm{C}$ to achieve a gas phase, and the products of their decomposition were collected by freezing on $\mathrm{KBr}$ windows for IR spectroscopy cooled to $-196{ }^{\circ} \mathrm{C}$ by liquid nitrogen. The IR spectra of these products were registered immediately, and contained a characteristic absorption band at $2122-2140 \mathrm{~cm}^{-1}$, that corresponded to $\mathrm{C}=\mathrm{C}=\mathrm{O}$ fragment of ketenes $\mathrm{A}$. This characteristic band in IR spectra disappeared as the temperature rose to between -105 and $-70{ }^{\circ} \mathrm{C}$, which demonstrated instability of acyl(imidoyl)ketenes A.

Such thermal instability of acyl(imidoyl)ketenes $\mathbf{A}$ is the origin of their high reactivity. In order to achieve thermodynamic stability, these compounds undergo various chemical immediate transformations, resulting in different heterocyclic compounds, which makes acyl(imidoyl)ketenes $\mathbf{A}$ a very interesting group of compounds from the theoretical point of view, as well as promising intermediates in the synthesis of various skeletally diverse heterocycles.

The present review summarizes patterns of immediate transformations of acyl(imidoyl) ketenes via intra- and intermolecular reactions, including the reactions of cyclodimerization, 
investigations on mechanisms, identifications of intermediates, and chemo- and regioselectivity of reactions with participation of acyl(imidoyl)ketenes. For the sake of simplicity, this review has been divided into three sections. The first shows general information on acyl(imidoyl)ketenes: possible applications in DOS, their structure from a symmetry point of view, approaches to their generation and data on the structure confirmation via FVT. In the second section, data on the immediate transformations of acyl(imidoyl)ketenes by intramolecular reactions are gathered and subdivided by the type of the formed heterocyclic product, while the third section contains data on intermolecular reactions and subdivided to cyclodimerization reactions and reactions with intercepting (trapping) reagents.

As acyl(imidoyl)ketenes $\mathbf{A}$ are highly reactive and unstable under the conditions of their generation (above $110^{\circ} \mathrm{C}$ ), most often, they are undetectable intermediates generated in situ. For this reason, in this review, acyl(imidoyl)ketenes $\mathbf{A}$ and other unstable, undetectable intermediates are given in square brackets.

\section{Immediate Transformations of Acyl(imidoyl)ketenes via Intramolecular Reactions}

\subsection{Intramolecular Cyclization of Acyl(imidoyl)ketenes to Quinoline-4(1H)-Ones}

Chemical behavior of acyl(imidoyl)ketenes $\mathbf{A}$ is dramatically dependent on the presence of nucleophilic centers spatial close to the ketene moiety $\mathrm{C}=\mathrm{C}=\mathrm{O}$. In particular, substituent at nitrogen atom in imidoyl moiety $\mathrm{C}=\mathrm{N}$ of acyl(imidoyl)ketenes $\mathrm{A}$ can be directly involved in intramolecular cyclizations, and the structure of products of such a transformation will depend on the nature of this substituent.

At thermolysis of 4-acyl-1-aryl-1H-pyrrole-2,3-diones 1.1, $\mathrm{N}$-aryl substituted acyl (imidoyl)ketenes $\mathbf{A} \mathbf{1}$ are generated, which undergo intramolecular cyclization through acylation of the ortho $\mathrm{CH}$ group of the benzene ring at nitrogen atom by the ketene moiety to result in quinoline-4(1H)-ones 5 (Scheme 3) [36-38,40,46-51]. The presence of one substituent in the ortho position of the benzene ring at nitrogen atom in 4-acyl-1-aryl-1Hpyrrole-2,3-diones $\mathbf{1 . 1}$ and, further, in ketenes A1, does not influence the reaction mode, and does not reduce the yields of compounds 5 , which reflects the ease of the intramolecular acylation process [47]. In addition, there is no noticeable effect of substituents in meta positions of the benzene ring at the nitrogen atom on the yield of the target products 5 [50].

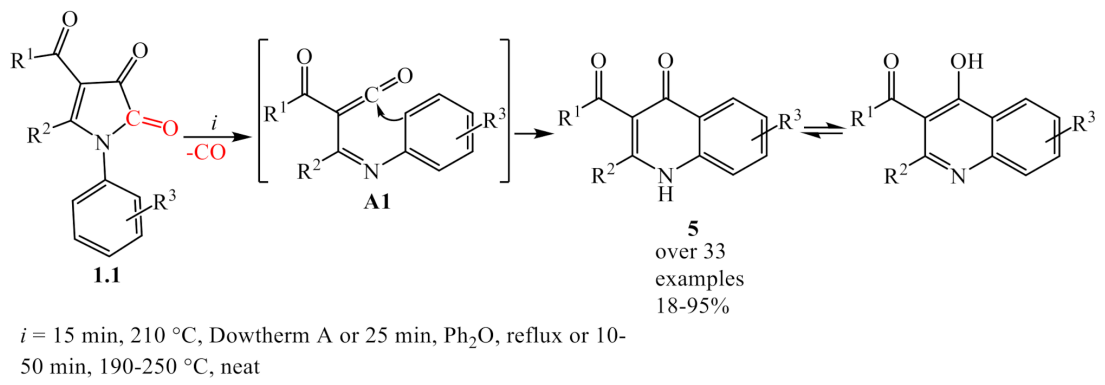

Scheme 3. Intramolecular cyclization of acyl(imidoyl)ketenes A1 to quinoline-4(1H)-ones 5.

There were attempts to trap ketenes $\mathbf{A} 1$ generated from monocyclic $1 H$-pyrrole-2,3diones 1.1 (Scheme 3 ) by various reagents ( $p$-methoxybenzaldehyde, benzonitrile, phenol, morpholine, and 2,4-dinitrophenylhydrazone of benzaldehyde) [47]. As a result, no intermolecular products were isolated, and reaction mixtures were turned into unidentified tars.

The mechanism of this transformation was studied using ${ }^{13} \mathrm{C}$ labels under FVT conditions $\left(650^{\circ} \mathrm{C}\right.$, gas phase) and under melting solid conditions $\left(250^{\circ} \mathrm{C}\right.$, phase transition from solid to liquid) [40]. 2,3-13 C-Labelled 4-benzoyl-1,5-diphenyl-1H-pyrrole-2,3-dione $\mathbf{1 . 1}$ was used as a starting material (Scheme 4). Under FVT conditions, a ketene-ketene rearrangement proceeding through a 1,3-shift of phenyl group with the formation of quinolones $5^{\prime}, 5^{\prime \prime}$ was observed. However, under common melting solid conditions of the starting pyrroledione 1.1, no rearrangement was observed, and quinolone $5^{\prime \prime \prime}$ was a single product. 


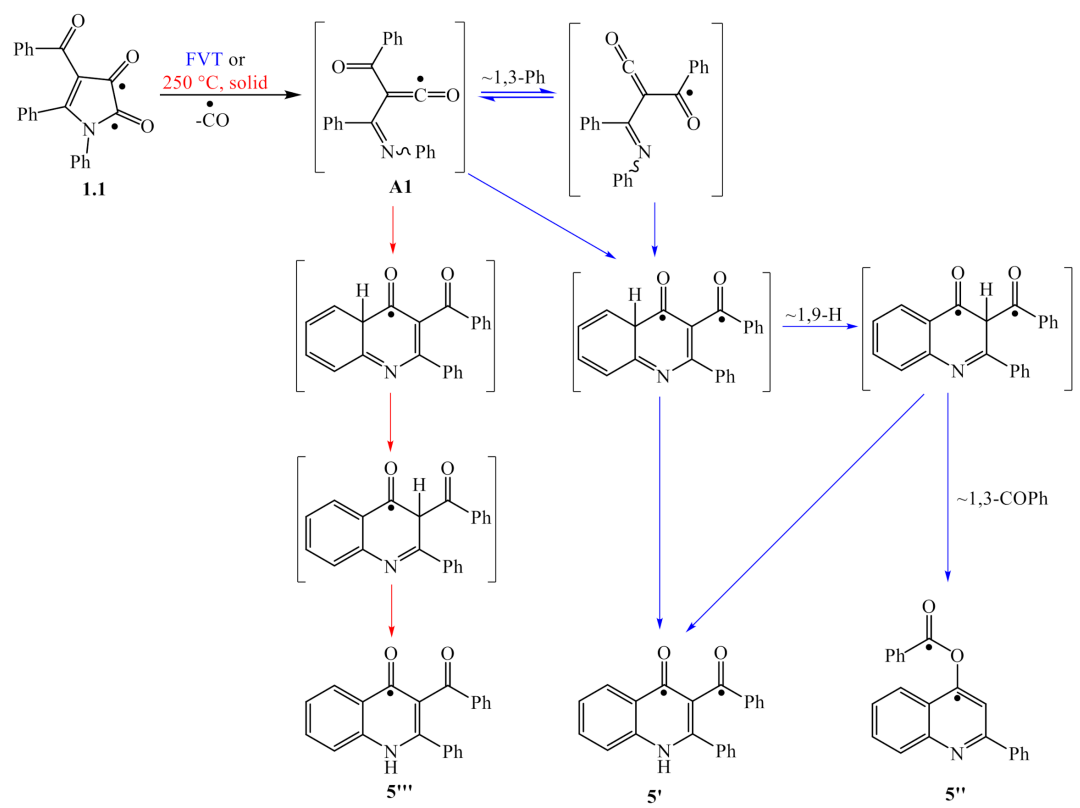

Scheme 4. The reaction mechanism study using ${ }^{13} \mathrm{C}$ labels $\left(\bullet={ }^{13} \mathrm{C}\right.$; red arrows are for melting solid conditions; blue arrows are for FVT conditions; and in structures of FVT pathway, the ${ }^{13} \mathrm{C}$ labels were in either one of the two positions indicated).

2.2. Intramolecular Cyclization of Acyl(imidoyl)ketenes to Furo[3,2-c]isoquinoline-2-Ones and 4-Aminofuran-2-Ones

Thermolysis of 4-acyl-1-benzyl-1H-pyrrole-2,3-diones $\mathbf{1 . 2}$ leads to the formation of acyl(N-benzylimidoyl)ketenes A2 (Scheme 5) [52]. N-Benzyl substituent plays an important role in further transformations of compounds $\mathbf{A} 2$ bearing it. Thus, acyl(N-benzylimidoyl) ketenes A2 undergo a [1,5]-prototropic shift (proton migrates from methylene group in benzyl moiety to the oxygen atom of acyl group) to result in hydroxyalkenyl ketenes B which undergo either intramolecular cyclization/reduction to 4-aminofuran-2-ones 6 or double intramolecular cyclization to 4,5-dihydrofuro[3,2-c]isoquinoline-2(3H)-ones $\mathbf{C}$. Then, intermediates $\mathbf{C}$ are oxidized to furo[3,2-c]isoquinolin-2-ones 7 (Scheme 5).

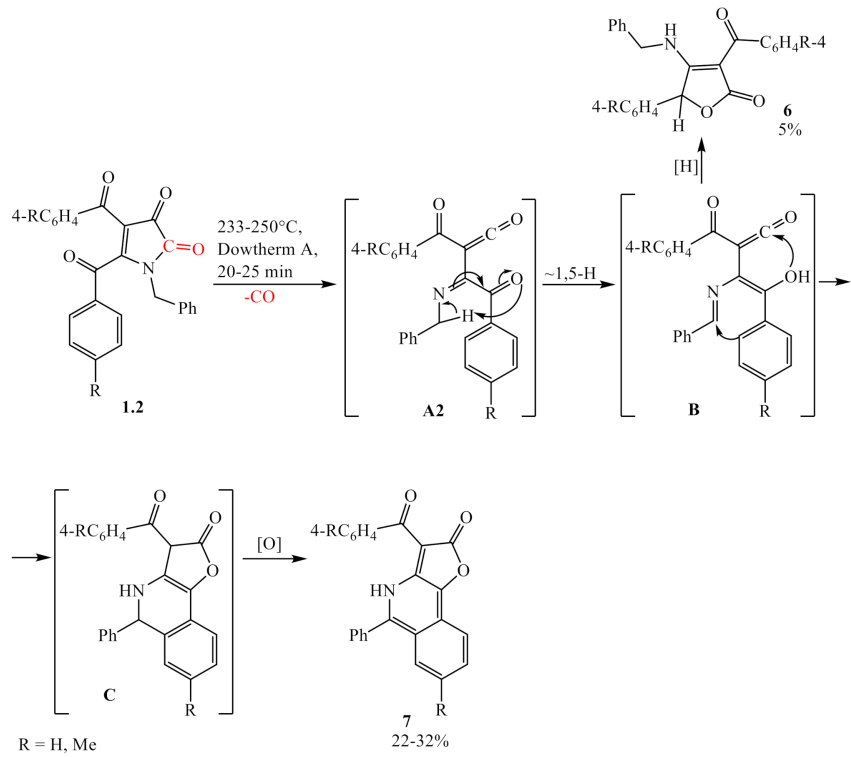

Scheme 5. Intramolecular cyclization of acyl(imidoyl)ketenes A2 to 4-aminofuran-2-ones 6 and furo[3,2-c]isoquinoline-2-ones 7. 


\subsection{Intramolecular Cyclization of Acyl(imidoyl)ketenes to Furo[3,2-b]quinoxalines}

Thermolysis of $N^{5}$-unsubstituted 3-acylpyrroloquinoxalinetriones 2.1 (analogs of 4acyl-1H-pyrrole-2,3-diones $\mathbf{1}$ discussed in the above sections, in which pyrrole core is fused with quinoxaline fragment) results in the formation of $\mathrm{N}^{4}$-unsubstituted acyl(quinoxalin2-yl)ketenes A3, in which imidoyl fragment $\mathrm{C}=\mathrm{N}$ is a part of quinoxaline substituent (Scheme 6). Acyl(quinoxalin-2-yl)ketenes A3 cannot undergo intramolecular cyclization to quinoline-4(1H)-ones 5 , as the ortho $\mathrm{CH}$ group of the benzene ring at $N^{1}$ atom is spatially too far away from ketene moiety $\mathrm{C}=\mathrm{C}=\mathrm{O}$. However, $\mathrm{N}^{4}$-unsubstituted acyl(quinoxalin-2yl)ketenes $\mathbf{A} 3$ still undergo intramolecular cyclization, in contrast to their $N^{4}$-substituted analogs, which are discussed below (Sections 3.1.1 and 3.2). $N^{4}$-Unsubstituted acyl(quinoxalin2-yl)ketenes A3 exist as two tautomers, amide and hydroxyimine. Hydroxyimine form contains $\mathrm{OH}$ group prone to react with ketene moiety to form furo[3,2-b]quinoxalines 8 [53-55] (Scheme 6). It should be mentioned that there were attempts to trap ketenes A3 by various dienophiles, but all of them were unsuccessful [55].
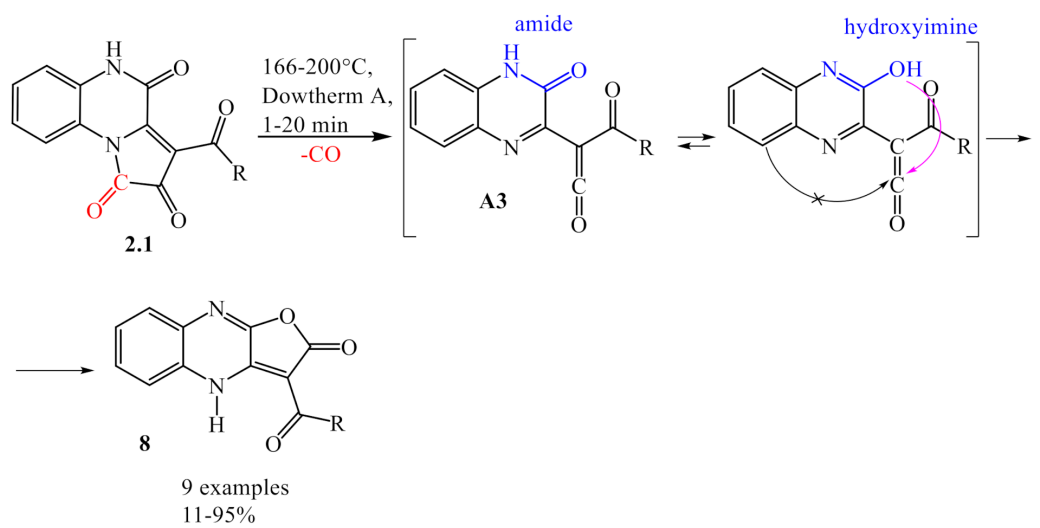

Scheme 6. Intramolecular cyclization of acyl(imidoyl)ketenes A3 to furo[3,2-b]quinoxalines 8.

\subsection{Intramolecular Cyclization of Acyl(imidoyl)ketenes to Benzo[e]pyrazolo[5,1-b][1,3]oxazines}

Installation of methyleneamino substituent at nitrogen atom of 4-acyl- $1 \mathrm{H}$-pyrrole-2,3diones 1.3 enables generation of peculiar acyl(imidoyl)ketenes A4 prone to intramolecular cyclization to zwitterions D1 (their bromine-free analogs are thoroughly discussed below (Sections 3.1.2 and 3.2)), through intramolecular attack of nitrogen atom of methyleneamino substituent on ketene moiety $\mathrm{C}=\mathrm{C}=\mathrm{O}$ (Scheme 7). As ketenes A4 bear (( (2bromophenyl)(phenyl)methylene)hydrazono) substituent, brominated zwitterions D1 undergo further intramolecular cyclization to brominated benzo[e]pyrazolo[5,1-b][1,3]oxazines E. Then, 1,3-sigmatropic shift of bromine occurs in intermediates $\mathbf{E}$ to result in intermediates F, which react with water to afford benzo[e]pyrazolo[5,1-b][1,3]oxazines 9 (Scheme 7) [56].

Interestingly, in the case of ketenes $\mathbf{A} 4$ bearing (((2-bromophenyl)(phenyl)methylene) hydrazono) substituent, formation of dimer compounds (which are discussed below (Section 3.1.2)) is not observed. In order to explain this fact, the mechanism of their transformation to compounds 9 and possible dimers was investigated by density functional theory (DFT) calculations [56]. The simplest system, $\mathbf{A} 4^{\prime}$, was used for the modelling (Scheme 8). It was found that the two transformations (path $A$ to the model of compounds 9 and path $B$ to the model of dimers) had a common, intermediate zwitterion, $\mathbf{D} \mathbf{1}^{\prime}$, formed via transition state TS1. Then, in path A, intermediate $\mathbf{E}^{\prime}$ was formed via the transition state TS2 in the result of a $6 \pi$-electrocyclic ring closure in intermediate $\mathbf{D} \mathbf{1}^{\prime}$. After that, intermediate $\mathbf{E}^{\prime}$ underwent a [1,3]-Cl shift via the transition state TS3 to afford compound $\mathbf{F}^{\prime}$, the model of compounds 9. In alternative path B, zwitterion $\mathbf{D 1}^{\prime}$ underwent dimerization in two stages. Firstly, polar dimeric structure G was formed via the transition state TS4. Secondly, structure $\mathbf{G}$ cyclized to form structure $\mathbf{H}$, model of dimers, via the transition state TS5. The free energy barriers calculations for the two alternative modes of transformation of ketene $\mathbf{A} 4^{\prime}$ revealed that structure $\mathbf{F}^{\prime}$ should be formed in the result of both the kinetical 
and thermodynamical control. Additionally, the formation of structure $\mathbf{H}$ should be an accessible process. The exclusive formation of structure $\mathbf{F}^{\prime}$ (Scheme 8) was explained by the lower thermodynamic stability of dimer $\mathbf{H}$ in relation to structure $\mathbf{F}^{\prime}$ and the entropic acceleration of the intramolecular cyclization process (path A) in comparison with the intermolecular dimerization (path B) [56].

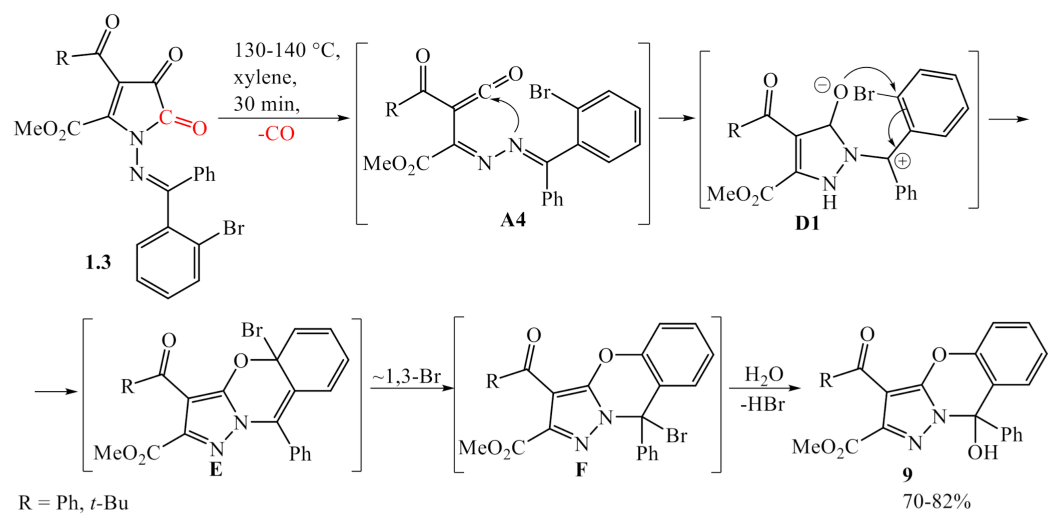

Scheme 7. Intramolecular cyclization of acyl(imidoyl)ketenes A4 to benzo[e]pyrazolo[5,1b][1,3]oxazines 9 via zwitterionic intermediates $\mathbf{D} 1$.

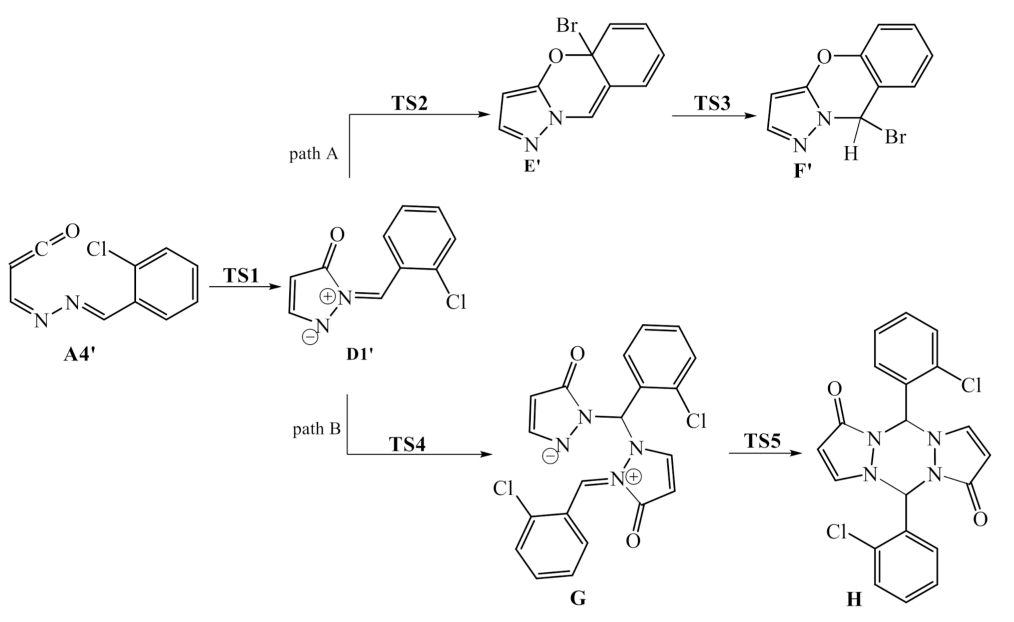

Scheme 8. DFT calculations of cyclization pathways of imidoylketene $\mathbf{A} 4^{\prime}$.

2.5. Intramolecular Cyclization of Acyl(imidoyl)ketenes to 1,8-Naphthyridines and 4H-Pyrido[1,2-a]pyrimidines

Thermolysis of diethyl 2-((pyridin-2-ylamino)methylene)malonates 4 leads to acyl (imidoyl)ketenes A5, which immediately undergoes intramolecular cyclization via acylation by ketene moiety of one of two reaction centers to afford 1,8-naphthyridines $\mathbf{1 0}$ (attack on the ortho- $\mathrm{CH}$ group) and/or $4 H$-pyrido[1,2-a]pyrimidines 11 (attack on the ortho-N atom) (Scheme 9) [42,43]. 4H-Pyrido[1,2-a]pyrimidines $\mathbf{1 1}$ are major products of this transformation under FVT (gas phase, contact times of $0.3 \mathrm{~s}, 450{ }^{\circ} \mathrm{C}$ ) conditions and are kinetic products. While in solution phase, the regioselectivity is highly dependent on the substituent position, as the cyclization is controlled by steric characteristics. Moreover, 1,8-naphthyridines 10 are formed as a result of thermal rearrangement of $4 H$-pyrido[1,2a]pyrimidines $\mathbf{1 1}$ and, thus, are considered to be thermodynamic products. 


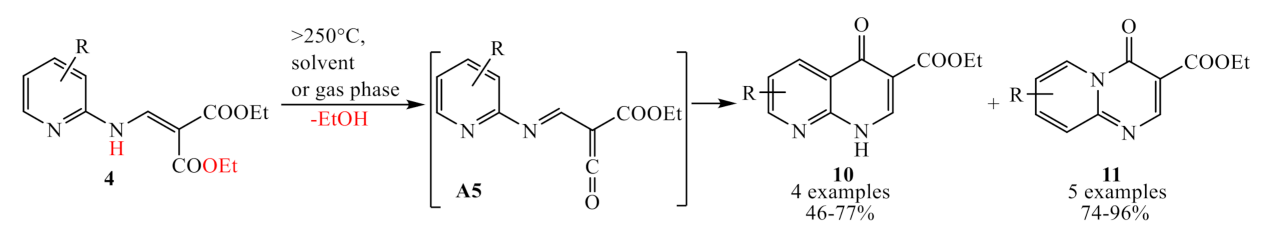

Scheme 9. Intramolecular cyclization of acyl(imidoyl)ketenes A5 to 1,8-naphthyridines $\mathbf{1 0}$ and 4H-pyrido[1,2-a]pyrimidines 11.

In order to explain the regioselectivity of this transformation, DFT calculations of cyclization of ketene A5 were performed (Scheme 10) [43]. According to the results of DFT calculations, after the formation of ketene A5, it underwent intramolecular cyclization at the nitrogen of the pyridyl-moiety to the kinetic product 11 via the transition state TS6. Then, product 11 rearranged to intermediate I via the transition state TS7. Finally, product $\mathbf{1 1}$ was tautomerized to the thermodynamic product 10. It should be emphasized that ketene A5 was found to be unable to cyclize directly to intermediate $\mathbf{I}$, as a corresponding intermediate or transition state were not located [43]. These results indicated that thermodynamic product $\mathbf{1 0}$ could only be formed from kinetic product $\mathbf{1 1}$.<smiles>CCOC(=O)c1c[nH]c2nc(C)ccc2c1=O</smiles>

Scheme 10. DFT calculations of cyclization of acyl(imidoyl)ketene A5.

\section{Immediate Transformations of Acyl(imidoyl)ketenes via Intermolecular Reactions}

Some structural features in the substituents of acyl(imidoyl)ketenes A make ketenes A unable to undergo reactions of intramolecular cyclization. In such cases, acyl(imidoyl) ketenes $\mathbf{A}$ become able to participate in reactions with themselves (dimerization) or other reagents (interception).

\subsection{Dimerization Reactions of Acyl(imidoyl)ketenes}

Depending on the structural features of the substituents in acyl(imidoyl)ketenes $\mathbf{A}$, their dimerization reactions can proceed through either [4+2]-cycloaddition reactions or zwitterionic ones.

\subsubsection{Cyclodimerization Reactions of Acyl(imidoyl)ketenes via [4+2]-Cycloaddition}

As acyl(imidoyl)ketenes $\mathrm{A}$ bear $\mathrm{C}=\mathrm{C}-\mathrm{C}=\mathrm{N}$ and $\mathrm{C}=\mathrm{C}-\mathrm{C}=\mathrm{O}$ diene fragments, which, hypothetically, can react with one another intermolecularly, both as dienes and dienophiles, one can assume that a difficult mixture of products would be formed in such reactions. However, experimental studies of cyclodimerization reactions of acyl(imidoyl)ketenes A have shown that, in their case, the reaction proceeds selectively, where one ketene $\mathrm{A}$ molecule acts as $\mathrm{C}=\mathrm{C}-\mathrm{C}=\mathrm{N}$ diene, and the other as $\mathrm{C}=\mathrm{C}$ dienophile, to form corresponding pyridine derivatives 12 (Scheme 11) [57-63].

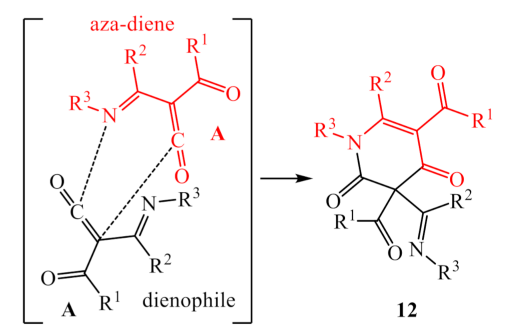

Scheme 11. Generalized scheme of cyclodimerization of acyl(imidoyl)ketenes A. 
This pattern of cyclodimerization is a characteristic of acyl(imidoyl)ketenes $\mathbf{A}$ generated from 4-acyl-1H-pyrrole-2,3-diones $\mathbf{2}$ fused at [e]-side with a heterocyclic fragment. Such acyl(imidoyl)ketenes A cannot undergo intramolecular cyclization (except for some cases such as $\mathrm{N}^{4}$-unsubstituted acyl(quinoxalin-2-yl)ketenes A3, Section 2.3), as ortho $\mathrm{CH}$ group of the benzene ring at $N^{1}$ atom or other nucleophilic centers are spatially too far away from ketene moiety $\mathrm{C}=\mathrm{C}=\mathrm{O}$ (Scheme 12). For example, such a pattern of immediate transformations is observed in the case of $N^{4}$-phenyl substituted acyl(quinoxalin-2-yl)ketenes A6 generated from $N^{5}$-phenyl substituted 3-acylpyrroloquinoxalinetriones 2.2 (Scheme 12) [57]. These $N^{4}$-phenyl substituted acyl(quinoxalin-2-yl)ketenes $\mathbf{A} \mathbf{6}$ undergo cyclodimerization via [4+2]-cycloaddition pathway, in which one ketene molecule plays the role of aza-diene, and the other one acts as $\mathrm{C}=\mathrm{C}$ dienophile, to form 9-(3-oxo-3,4-dihydroquinoxalin-2-yl)-5Hpyrido[1,2-a]quinoxaline-6,8,10(9H)-triones 12.1 (Scheme 12) [57].

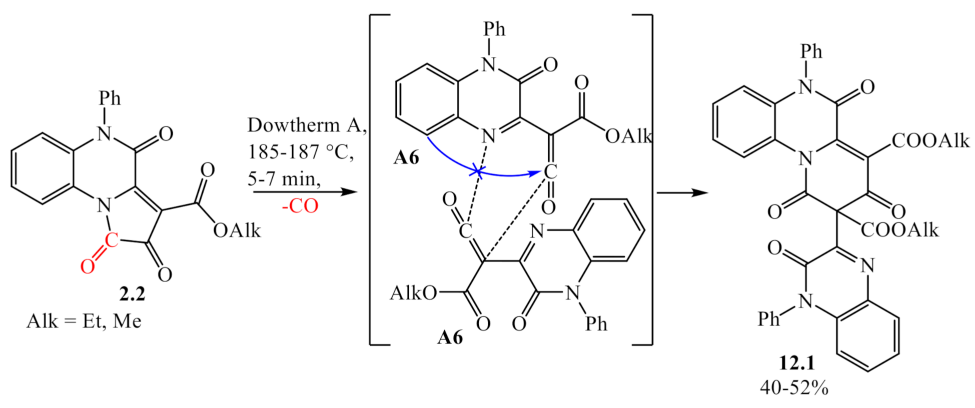

Scheme 12. Cyclodimerization of acyl(imidoyl)ketenes $\mathbf{A 6}$ to 9-(3-oxo-3,4-dihydroquinoxalin-2-yl)$5 H$-pyrido[1,2-a]quinoxaline-6,8,10(9H)-triones $\mathbf{1 2 . 1}$.

Interestingly, acyl(imidoyl)ketenes A6-A8 of this type, bearing aroyl substituent COAr as acyl group, participate in the same type of cyclodimerization as their alkoxycarbonyl COOAlk analogs (structures A6, Scheme 12), but formed products 12 undergo 1,3-acylotropic shift to result in compounds 13 (Scheme 13) [58-63].

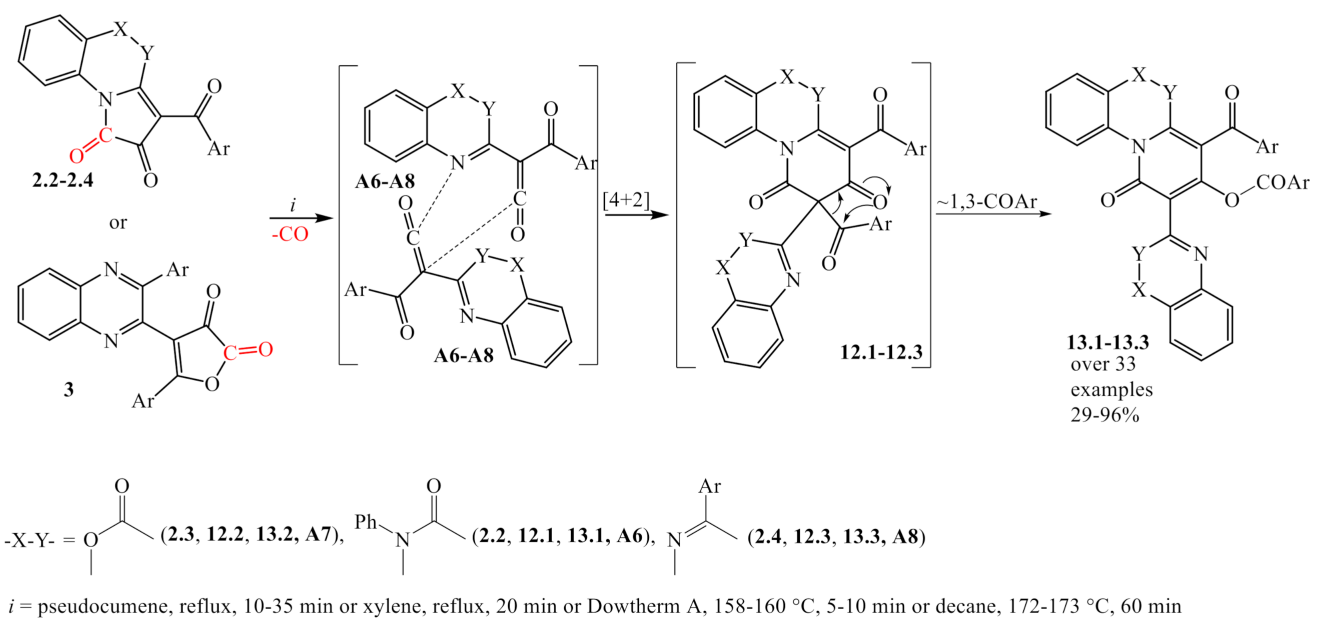

Scheme 13. Cyclodimerization of acyl(imidoyl)ketenes A6-A8 bearing aroyl substituent COAr to compounds 13 accompanied by 1,3-acylotropic shift.

3.1.2. Dimerization Reactions of Acyl(imidoyl)ketenes via Intramolecular Cyclization of Them to Zwitterions

Immediate transformation of acyl(imidoyl)ketenes $\mathbf{A}$ bearing methyleneamino substituent at nitrogen atom is accompanied by the formation of zwitterions $\mathbf{D}$, existing in two tautomeric forms, 1,3-CNN-dipole and 1,4-CNCO-dipole (Scheme 14) [64,65]. 


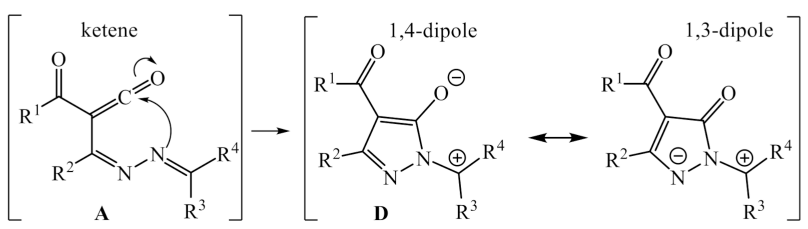

Scheme 14. Immediate transformation of acyl(imidoyl)ketenes A bearing methyleneamino substituent at nitrogen atom to zwitterions $\mathbf{D}$.

These types of methyleneamino substituted acyl(imidoyl)ketenes $\mathbf{A} 9$ are readily generated from 1-[(diphenylmethylidene)amino] substituted 4-acyl-1H-pyrrole-2,3-diones 1.4 (Scheme 15) [64,65]. Formed zwitterions D2 undergo dimerization reaction through two possible pathways in the dependence on the type of acyl substituent COR. When acyl substituent is pivaloyl $(\mathrm{R}=t$-Bu), zwitterions $\mathbf{D} 2$ participate in [3+3]-cycloaddition reaction as 1,3-dipoles to form symmetric tetrazines $\mathbf{1 4}$, and when acyl substituent is aroyl ( $\mathrm{R}=\mathrm{Ar}$ ), zwitterions D2 participate in [4+4]-cycloaddition reaction as 1,4-dipoles to form symmetric bis-pyrazolodioxadiazocines $\mathbf{1 5}$ (Scheme 15). Formation of compounds $\mathbf{1 5}$ is a reversible process, which is indicated visually by the change of their solutions' color from colorless to dark blue when their solutions are heated, and vice versa, when cooled $[64,65]$. Due to this property, compounds $\mathbf{1 5}$ can be successfully used in synthetic procedures as a source of zwitteriones D2 [65].

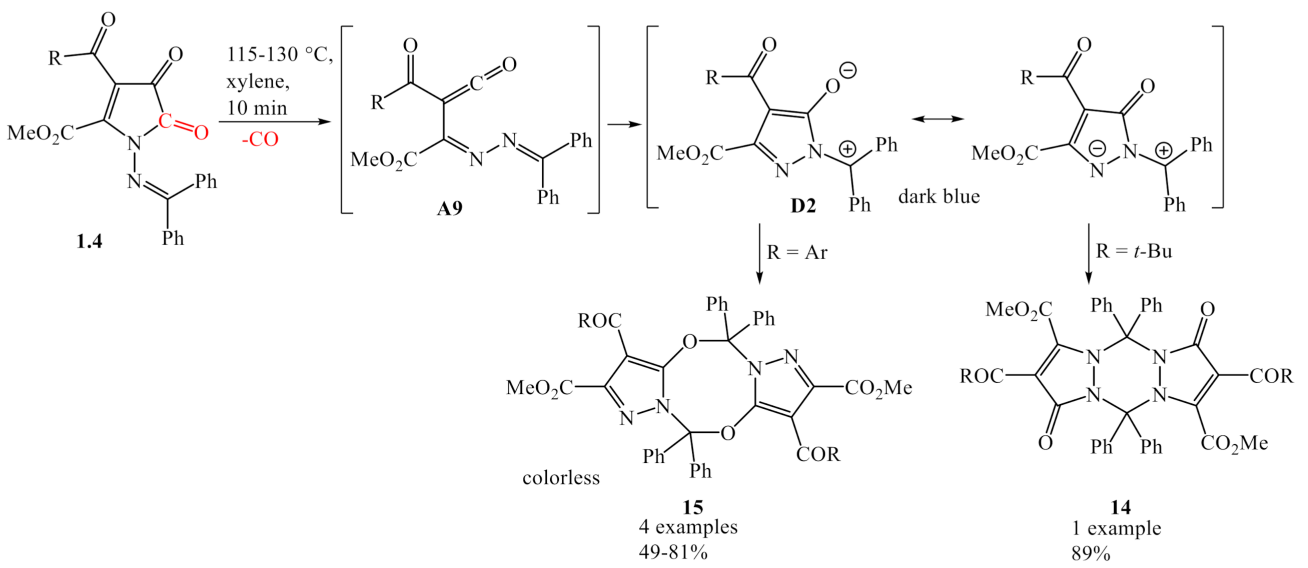

Scheme 15. Pathways of immediate transformation of zwitterions D2 generated from acyl(imidoyl)ketenes A9 to tetrazines 14 and bis-pyrazolodioxadiazocines 15.

It should be emphasized that formation of compounds 14, 15 is not observed in the case of similar ketenes A4 bearing (((2-bromophenyl)(phenyl)methylene)hydrazono) substituent, apparently due to the fact that corresponding zwitterions D1 quickly undergo intramolecular cyclization to benzo[e]pyrazolo[5,1-b][1,3]oxazines 9 (Scheme 9, Section 2.4) [56].

In addition, 1-diphenylamino substituted 4-acyl-1H-pyrrole-2,3-diones 1.5 do not afford acyl(imidoyl)ketenes A10 prone to formation of zwitterions (Scheme 16) [66]. Instead, when heated, compounds $\mathbf{1 . 5}$ undergo a kinetically controlled isomerization to 1,3a,8,8a-tetrahydropyrrolo[2,3- $b$ ]indole-2,3-diones 16 . Further heating of pyrrolo[2,3b]indole-2,3-diones 16, which have a benzoyl substituent at $C^{3 a}$, results in isomerization to thermodynamically stable $\mathrm{N}$-(2-(1,2-diphenyl- $1 \mathrm{H}$-indole-3-yl)-2-oxoacetyl)benzamide $\mathbf{1 7}$ (Scheme 16). However, the heating an analogous pyrrolo[2,3-b] indole-2,3-dione 16, bearing an ester group at $C^{3 a}$, leads to another thermolysis product, ethyl 1,2-diphenyl-1 $H$-indole3-carboxylate 18 (Scheme 16). 


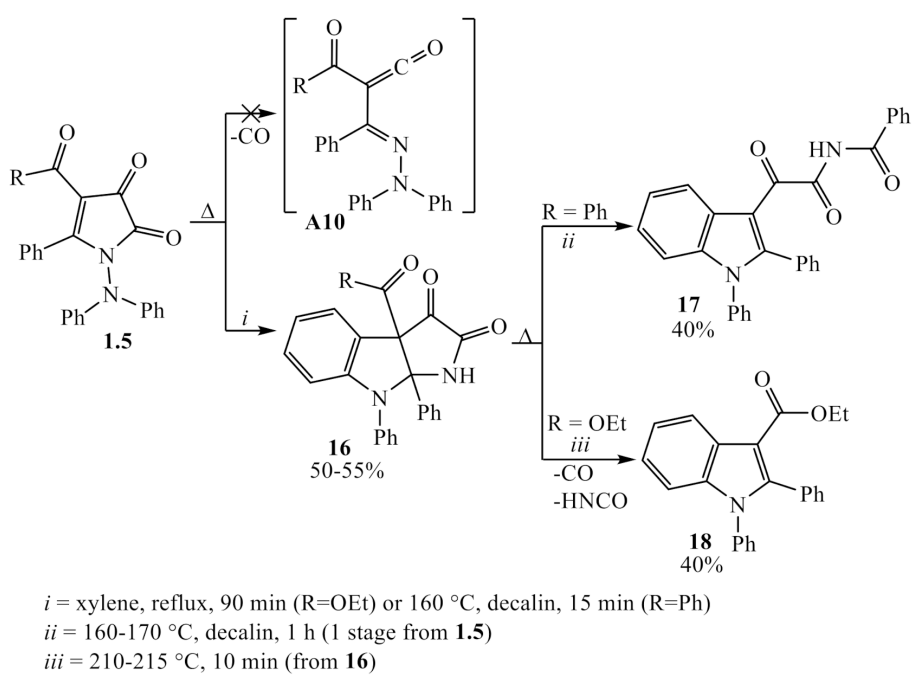

Scheme 16. Thermolysis of 4-acyl-1-(diphenylamino)-5-phenyl-1H-pyrrole-2,3-diones 1.5 without formation of acyl(imidoyl)ketenes A10.

\subsection{Interception Reactions of Acyl(imidoyl)ketenes}

Acyl(imidoyl)ketenes $\mathbf{A 6} \mathbf{- A 9}$ capable to participate in dimerization reactions are able to take part in reactions with some other reagents (interception reactions) to form various heterocycles. Alkenes, imines, carbonyl compounds, nitriles, isocyanides, carbodiimides, etc. can act as interceptors (trapping reagents).

\subsubsection{Interception Reactions of Acyl(imidoyl)ketenes with Alkenes}

Zwitterions D2, formed as a result of intramolecular cyclization of methyleneamino substituted acyl(imidoyl)ketenes $\mathbf{A 9}$, react with alkenes $\mathbf{1 8}$ to afford pyrazolo[5,1-b][1,3] oxazines 19 (Scheme 17) [64,67]. This reaction proceeds regioselectively; zwitterions D react as 1,4-CNCO-dipoles, and alkenes 18 react as $\mathrm{C}=\mathrm{C}$ dipolarophiles. Trapping reagents $\mathbf{1 8}$ are added to the reaction mixture after thermolysis of compounds $\mathbf{1 . 4}$ is finished.
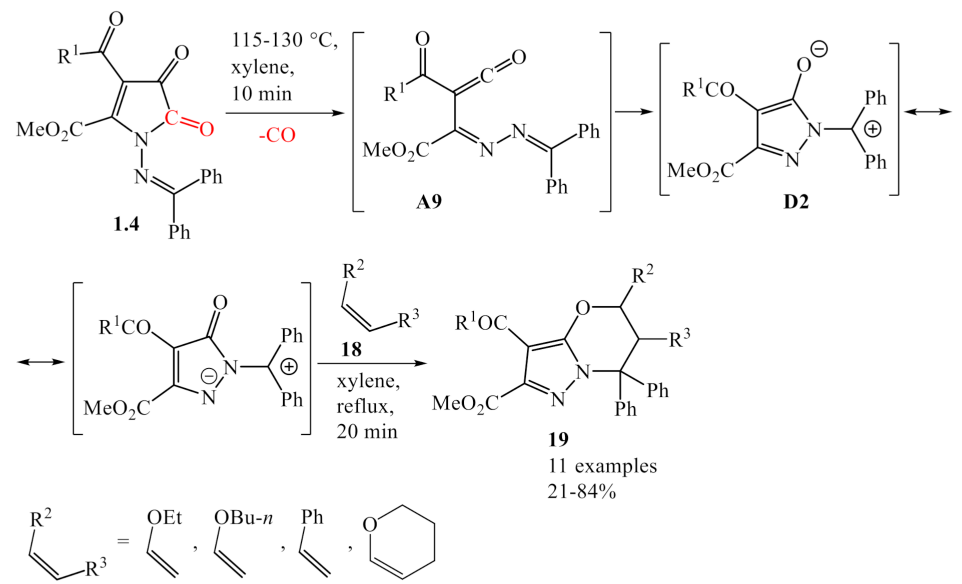

Scheme 17. Interception of zwitterions D2, formed from methyleneamino substituted acyl(imidoyl)ketenes $\mathbf{A 9}$, by alkenes $\mathbf{1 8}$ with formation of pyrazolo[5,1-b][1,3] oxazines 19 .

There are no reports on reactions of other acyl(imidoyl)ketenes $\mathbf{A}$ with alkenes, as precursors of these ketenes, compounds 1,2 , react with alkenes 18 at temperatures lower than required for the generation of acyl(imidoyl)ketenes $\mathbf{A}[38,46]$, and carrying out this reaction by adding alkenes $\mathbf{1 8}$ after the generation of ketenes $\mathbf{A}$ is impossible due to the very short lifetime of ketenes $\mathbf{A}$. 


\subsubsection{Interception Reactions of Acyl(imidoyl)ketenes with Carbonyl Compounds}

Acyl(imidoyl)ketenes A8 generated from (quinoxalin-2-yl)furan-2,3-diones $\mathbf{3}$ react with carbonyl compounds 20 (aldehydes and ketones) to form exclusively 5-(quinoxalin-2yl)-4H-1,3-dioxin-4-ones 21 (Scheme 18) [68,69]. Trapping reagents 20 are added directly to the reaction mixture before heating. Ketenes $\mathbf{A}$ react as oxa-dienes, and carbonyl compounds 20 react as oxa-dienophiles. The reaction proceeds regioselectively, and formation of alternative products, [1,3] oxazino[3,4-a]quinoxalin-3-ones $\mathbf{J}$, is not observed (Scheme 18).

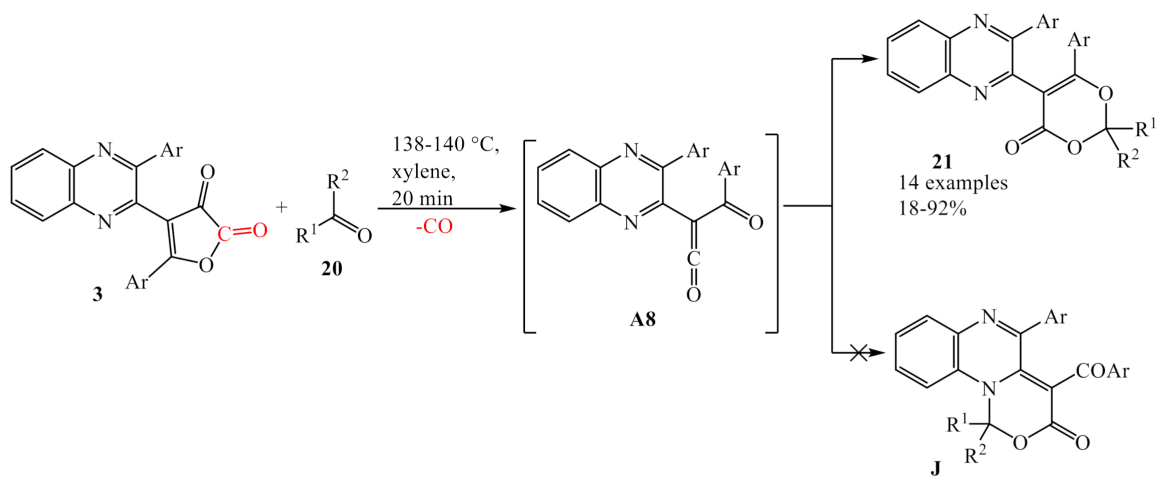

Scheme 18. Interception of acyl(imidoyl)ketenes A8 by carbonyl compounds 20 with formation of 5-(quinoxalin-2-yl)-4H-1,3-dioxin-4-ones 21.

The reaction of acyl(imidoyl)ketenes A8 with allobetulone proceeds in a similar way to result in corresponding derivatives 21 (Scheme 18) [68]. However, a similar reaction of ketenes $\mathbf{A} 8$ with camphor does not produce desired derivatives $\mathbf{2 1}$ nor derivatives $\mathbf{J}$, and instead products of dimerization of acyl(imidoyl)ketenes $\mathbf{A} 8$ to compounds $\mathbf{1 3 . 3}$ are observed [68]. Such a change in regioselectivity of the reaction may be caused by steric difficulties created by the three methyl groups in camphor [68].

In addition, $\mathrm{N}^{4}$-substituted acyl(quinoxalin-2-yl)ketenes $\mathbf{A 6}$ generated from $\mathrm{N}^{5}$ substituted 3-acylpyrroloquinoxalinetriones 2.2 do not react with carbonyl compounds 20 [70].

Acyl(imidoyl)ketenes A7 generated from 3-aroylpyrrolobenzoxazinetriones 2.3 nonselectively react with aromatic aldehydes 20 to form a mixture of 3-(4-oxo- $4 \mathrm{H}-1,3$-dioxin-5yl)-2H-benzo[b][1,4]oxazin-2-ones 22 and $1 H$-benzo[5,6][1,4] oxazino[4,3-c][1,3]oxazine-3,5diones 23 (Scheme 19) [71]. Trapping reagents 20 are added directly to the reaction mixture before heating. Such a change in selectivity of reaction of acyl(imidoyl)ketenes A7 [71], in comparison with acyl(imidoyl)ketenes A8 [68,69], can be caused by two factors. It can be connected to the influence of heterocyclic substituent incorporating imidoyl moiety $\mathrm{C}=\mathrm{N}$ of ketenes $\mathbf{A}$ or to the influence of reaction temperature (it is much lower in the case of ketenes A8).

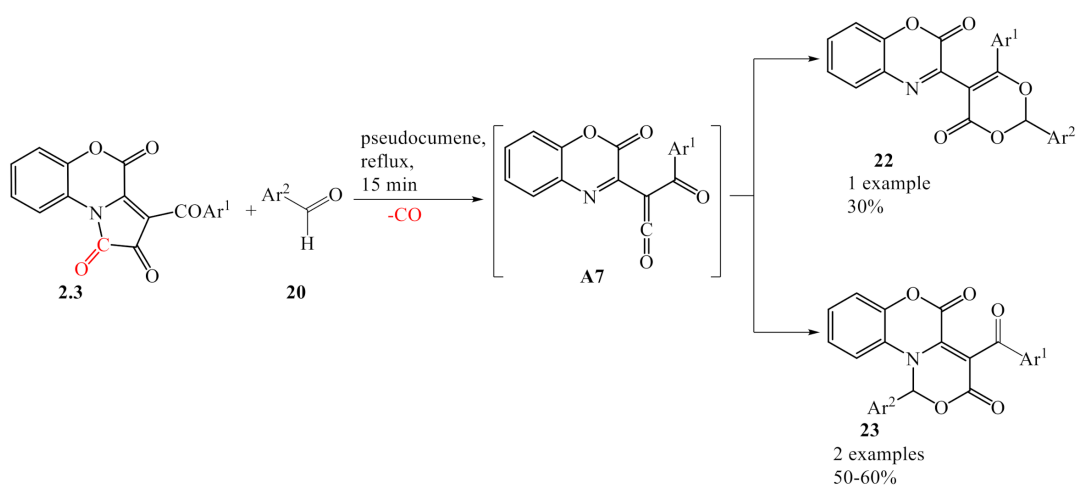

Scheme 19. Interception of acyl(imidoyl)ketenes $\mathbf{A} 7$ by aromatic aldehydes 20 with formation of 3-(4-oxo-4H-1,3-dioxin-5-yl)-2H-benzo[b][1,4]oxazin-2-ones 22 and $1 H$-benzo[5,6][1,4]oxazino[4,3c][1,3] oxazine-3,5-diones 23 . 
Zwitterions D2, formed as a result of intramolecular cyclization of methyleneamino substituted acyl(imidoyl)ketenes A9 or thermal dissociation of symmetric bispyrazolodioxadiazocines 15, react with carbonyl compounds 20 (aldehydes or ketones) to afford pyrazolo[5,1-b][1,3]oxazines 24 (Scheme 20) [64,65]. This reaction proceeds regioselectively; zwitterions $\mathbf{D} 2$ react as 1,4-CNCO-dipoles, and carbonyl compounds 20 react as $\mathrm{C}=\mathrm{O}$ dipolarophiles. In the case of synthesis via thermolysis of compounds 1.4, trapping reagents $\mathbf{2 0}$ are added to the reaction mixture after thermolysis of compounds $\mathbf{1 . 4}$ is finished [64]. In the case of synthesis via thermal dissociation of compounds 15, trapping reagents 20 are added to the reaction before heating, and the reaction can be carried out under solvent-free conditions [65].
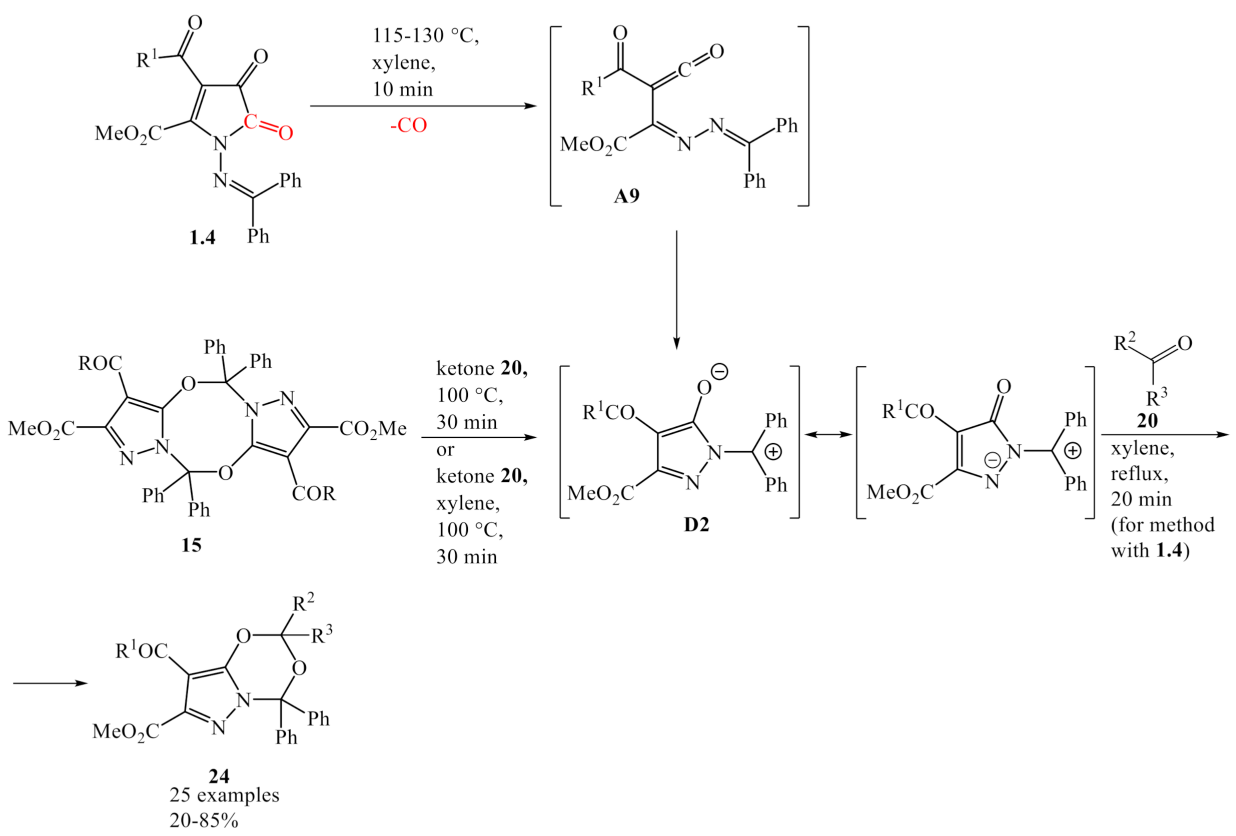

Scheme 20. Interception of zwitterions D2, formed from methyleneamino substituted acyl(imidoyl)ketenes A9 or from bis-pyrazolodioxadiazocines 15, by carbonyl compounds 20 with formation of pyrazolo[5,1- $d][1,3,5]$ dioxazines 24 .

Synthetic approach based on generation of zwitterions D2 via intramolecular cyclization of methyleneamino substituted acyl(imidoyl)ketenes A9 obtained from thermolysis of compounds $\mathbf{1 . 4}$ is suitable for the reaction with aromatic aldehydes 20 [64], and the approach through thermal dissociation of symmetric bis-pyrazolodioxadiazocines $\mathbf{1 5}$ is suitable for reactions with ketones 20 [65]. This can be explained by the fact that products 24, derived from ketones $\mathbf{2 0}$, are less thermally stable than their analogs derived from aldehydes $\mathbf{2 0}$ and, thus, lower reaction temperatures are required for their synthesis, which is easily achieved in the approach via bis-pyrazolodioxadiazocines 15.

\subsubsection{Interception Reactions of Acyl(imidoyl)ketenes with Nitriles and Isocyanides}

Acyl(imidoyl)ketenes A8 generated from (quinoxalin-2-yl)furan-2,3-diones 3 react with cyanamides 25 to form 5-(quinoxalin-2-yl)-4H-1,3-oxazin-4-ones $\mathbf{2 6}$ as sole products (Scheme 21) [72]. Trapping reagents 25 are added directly to the reaction mixture before heating. Ketenes $\mathbf{A} 8$ react as oxa-dienes, and cyanamides $\mathbf{2 5}$ react as aza-dienophiles. The reaction proceeds regioselectively, and formation of alternative products, $3 \mathrm{H}$-pyrimido[1,6a]quinoxalin-3-ones $\mathbf{K}$, is not observed (Scheme 21). It should be mentioned that ketenes A8 do not react with acetonitrile and substituted benzonitriles 27 [72]. In this case, only dimers $\mathbf{1 3 . 3}$ are isolated as products. 


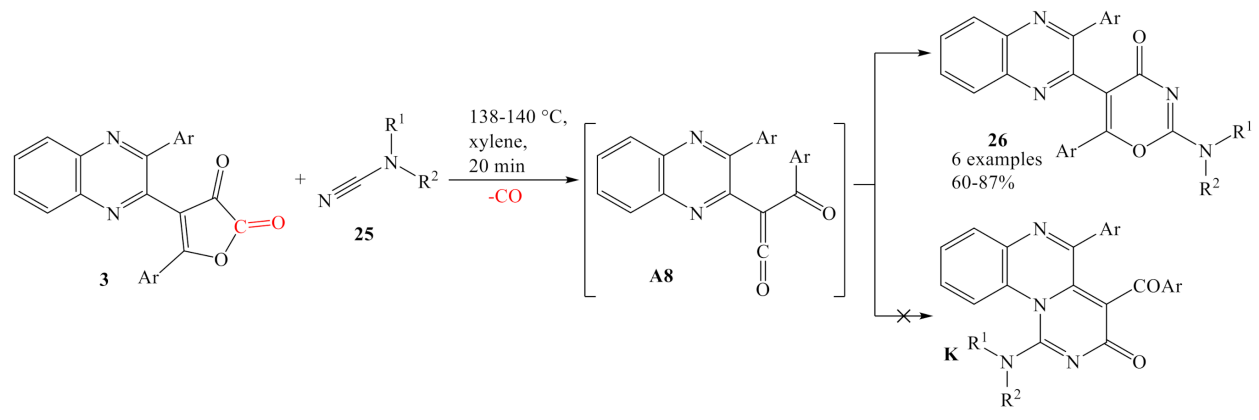

Scheme 21. Interception of acyl(imidoyl)ketenes A8 by cyanamides 25 with formation of 5(quinoxalin-2-yl)-4H-1,3-oxazin-4-ones 26.

In addition, $N^{4}$-substituted acyl(quinoxalin-2-yl)ketenes $\mathbf{A 6}$ generated from $\mathrm{N}^{5}$ substituted 3-acylpyrroloquinoxalinetriones 2.2 do not react with benzonitriles 27 [70]. Additionally, their reaction with cyanamides 25 proceeded before thermal decarbonylation, and unspecified adducts of compound $\mathbf{2 . 2}$ with cyanamides $\mathbf{2 5}$ were detected as the major components of the reaction mixtures [70].

Zwitterions D2, formed as a result of intramolecular cyclization of methyleneamino substituted acyl(imidoyl)ketenes A9, react with substituted benzonitriles $\mathbf{2 7}$ to afford $4 H$-pyrazolo[5,1-b][1,3,5]oxadiazines 28 (Scheme 22) [64]. This reaction proceeds regioselectively; zwitterions $\mathbf{D} 2$ react as 1,4-CNCO-dipoles, and benzonitriles 27 react as $\mathrm{C} \equiv \mathrm{N}$ dipolarophiles. Trapping reagents 27 are added to the reaction mixture after thermolysis of compounds 1.4 is finished.

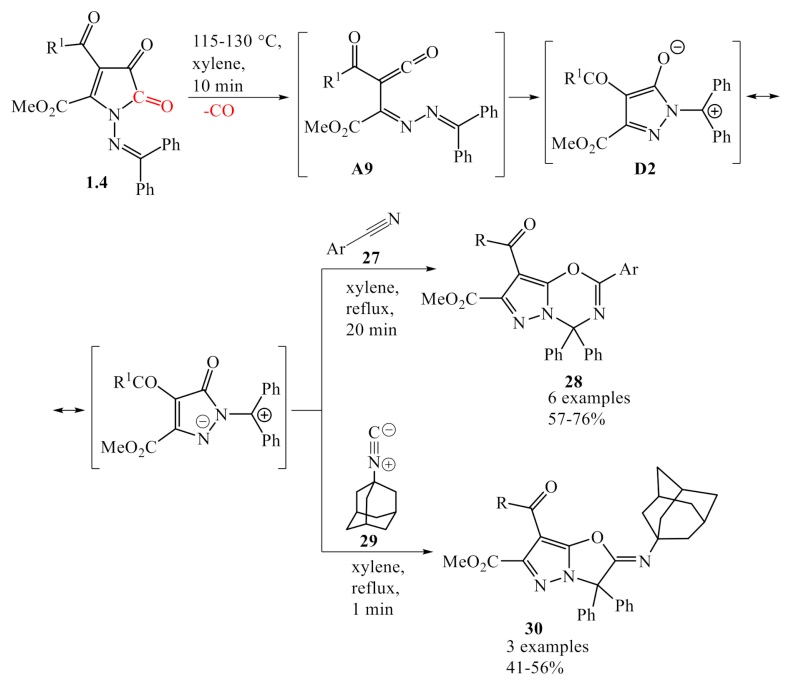

Scheme 22. Interception of zwitterions D2, formed from methyleneamino substituted acyl(imidoyl)ketenes $\mathbf{A 9}$, by benzonitriles 27 and 1-isocyanoadamantane 29 with formation of $4 \mathrm{H}$ pyrazolo[5,1- $b][1,3,5]$ oxadiazines 28 and pyrazolo[5,1- $b$ ] oxazoles 30 , respectively.

Similar reaction of 1-isocyanoadamantane 29 with zwittreions D2 affords pyrazolo[5,1b] oxazoles 30 (Scheme 22) [64]. This reaction proceeds regioselectively too; zwitterions D2 react as 1,4-CNCO-dipoles, and 1-isocyanoadamantane 30 react as carbene. Trapping reagent $\mathbf{3 0}$ is added to the reaction mixture after thermolysis of compounds $\mathbf{1 . 4}$ is finished.

3.2.4. Interception Reactions of Acyl(imidoyl)ketenes with Carbodiimides and Schiff Bases

Acyl(imidoyl)ketenes A8 generated from (quinoxalin-2-yl)furan-2,3-diones $\mathbf{3}$ react as oxa-dienes with Schiff bases 31 and carbodiimides 32 to form 5-(quinoxalin-2-yl)-2,3dihydro-4H-1,3-oxazin-4-ones 33, 34 (Scheme 23) [73]. Trapping reagents 31, 32 are added directly to the reaction mixture before heating. The reaction proceeds regioselectively, and 
no formation of alternative products of cycloaddition at aza-diene system of ketenes A8 is observed.

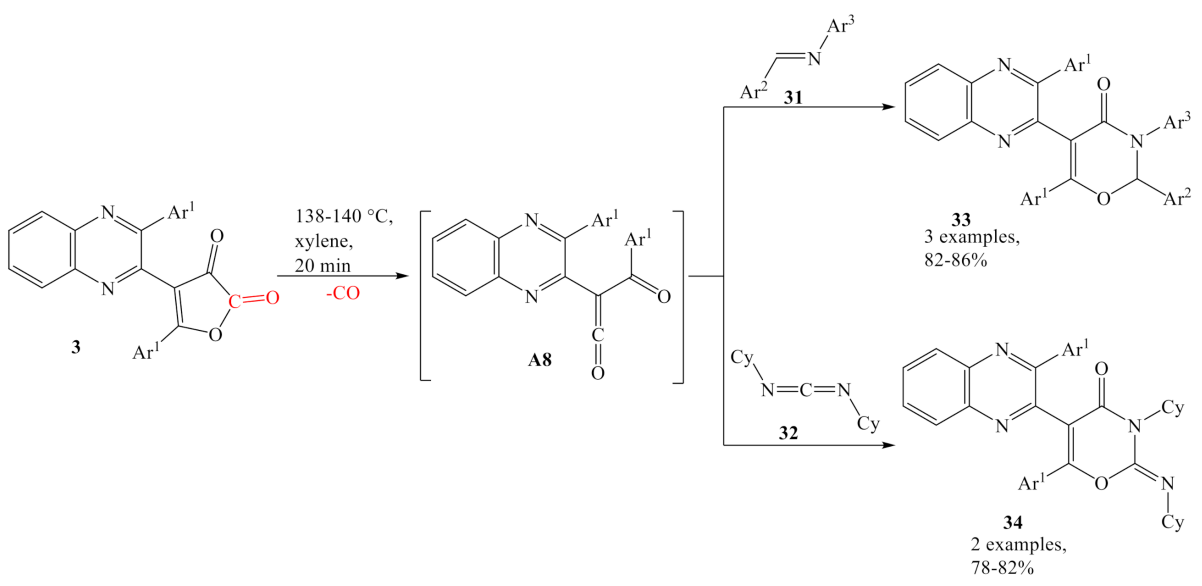

Scheme 23. Interception of acyl(imidoyl)ketenes $\mathbf{A} 8$ by Schiff bases $\mathbf{3 1}$ and carbodiimides $\mathbf{3 2}$ with formation of 5-(quinoxalin-2-yl)-2,3-dihydro-4H-1,3-oxazin-4-ones 33, 34, respectively.

Interestingly, $N^{4}$-phenyl substituted acyl(quinoxalin-2-yl)ketenes $\mathbf{A 6}$ generated from $N^{5}$-phenyl substituted 3-acylpyrroloquinoxalinetriones $\mathbf{2 . 2}$ react as aza-dienes with Schiff bases 31 to form 1,2-dihydro-3H-pyrimido[1,6-a]quinoxaline-3,5(6H)-diones 35 as sole products (Scheme 24) [54]. Trapping reagents 31 are added directly to the reaction mixture before heating; the reaction can be performed in a solvent-free mode. The reaction proceeds regioselectively, and no formation of alternative products of cycloaddition at oxa-diene system of ketenes A6 is observed [54]. Such a change in regioselectivity of reaction of acyl(imidoyl)ketenes A6 [54], in comparison with acyl(imidoyl)ketenes A8 [73], can be caused rather by the influence of heterocyclic substituent incorporating imidoyl moiety $\mathrm{C}=\mathrm{N}$ of ketenes $\mathrm{A}$ or to the influence of reaction temperature (it is lower in the case of ketenes A8).

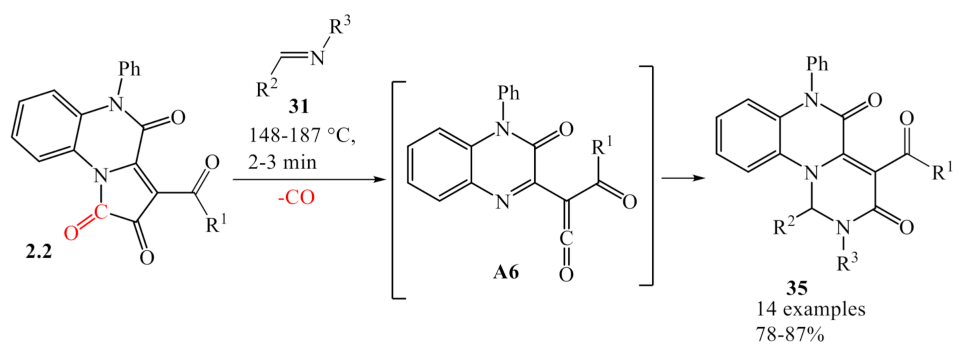

Scheme 24. Interception of acyl(imidoyl)ketenes A6 by Schiff bases 31 with formation of 1,2-dihydro$3 H$-pyrimido[1,6-a]quinoxaline-3,5(6H)-diones 35.

However, $N^{4}$-substituted acyl(quinoxalin-2-yl)ketenes $\mathbf{A 6}$ generated from $N^{5}$-substituted 3-acylpyrroloquinoxalinetriones 2.2 react with carbodiimides 32 to form 1,2-dihydro$3 \mathrm{H}$-pyrimido[1,6-a]quinoxaline-3,5(6H)-diones 36 or 5-(3-oxo-3,4-dihydroquinoxalin-2-yl)2,3-dihydro-4H-1,3-oxazin-4-ones 37 in dependence on type of acyl substituent $\mathrm{COR}^{2}$ (Scheme 25) [70]. When $\mathrm{R}^{2}$ is aryl, reaction occurs at $\mathrm{C}=\mathrm{C}-\mathrm{C}=\mathrm{O}$ system, and compounds 36 are formed, and when $\mathrm{R}^{2}$ is alkoxy or $t$-butyl, reaction occurs at $\mathrm{C}=\mathrm{C}-\mathrm{C}=\mathrm{N}$ system, and compounds 37 are formed. Trapping reagents 32 are added directly to the reaction mixture before heating; the reaction can be performed in a solvent-free mode. The reaction proceeds regioselectively in both cases, and no formation of alternative products of cycloaddition is observed [54]. 


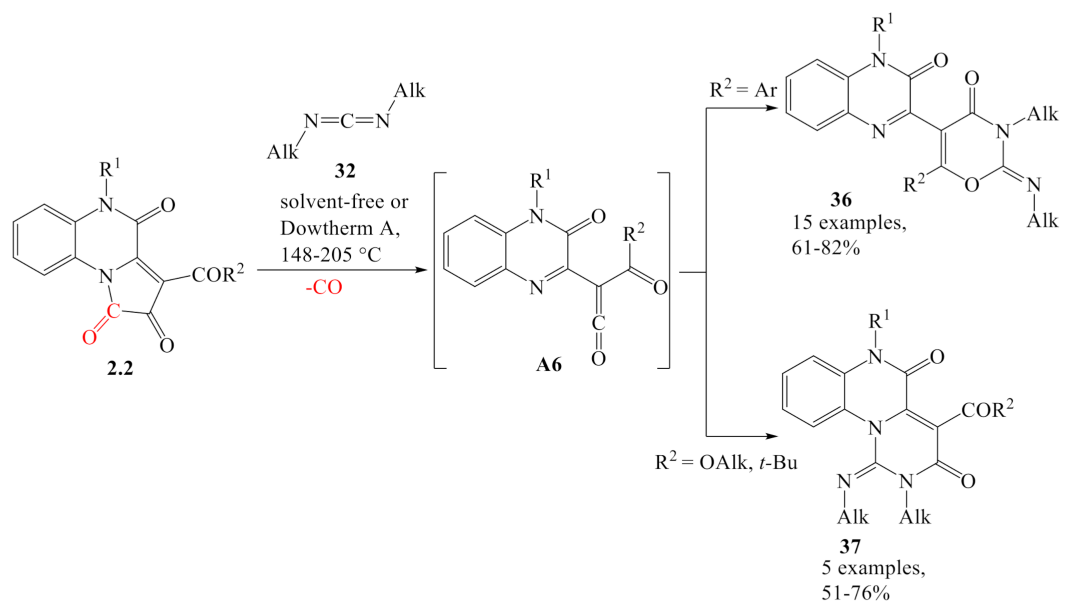

Scheme 25. Interception of acyl(imidoyl)ketenes A6 by carbodiimides 32 with formation of 1,2dihydro-3H-pyrimido[1,6- $a$ ]quinoxaline-3,5(6H)-diones 36 or 5-(3-oxo-3,4-dihydroquinoxalin-2-yl)2,3-dihydro-4H-1,3-oxazin-4-ones 37.

Such a regioselectivity switch by acyl substituents $\mathrm{COR}^{2}$ (Scheme 25) can be explained by intractability of COOAlk and COBu- $t$ groups to participate in hetero-DielsAlder reaction.

A similar regioselectivity switch is observed in the case of trapping of acyl(imidoyl) ketenes A7 generated from 3-aroylpyrrolobenzoxazinetriones $\mathbf{2 . 3}$ by Schiff bases $\mathbf{3 1}$ and carbodiimides 32 (Scheme 26) [61,74]. However, in this case, regioselectivity depends on the type or trapping reagent. Schiff bases 31 promote cycloaddition at $\mathrm{C}=\mathrm{C}-\mathrm{C}=\mathrm{N}$ fragment to form 1,2-dihydrobenzo[b]pyrimido[1,6-d][1,4] oxazine-3,5-diones 38, and carbodiimides 32, at $\mathrm{C}=\mathrm{C}-\mathrm{C}=\mathrm{O}$ fragment to form 3-(2-imino-4-oxo-3,4-dihydro-2 $\mathrm{H}$-1,3-oxazin-5-yl)-2 $\mathrm{H}$ benzo[b][1,4]oxazin-2-ones 39 . Trapping reagents 31,32 are added directly to the reaction mixture before heating.

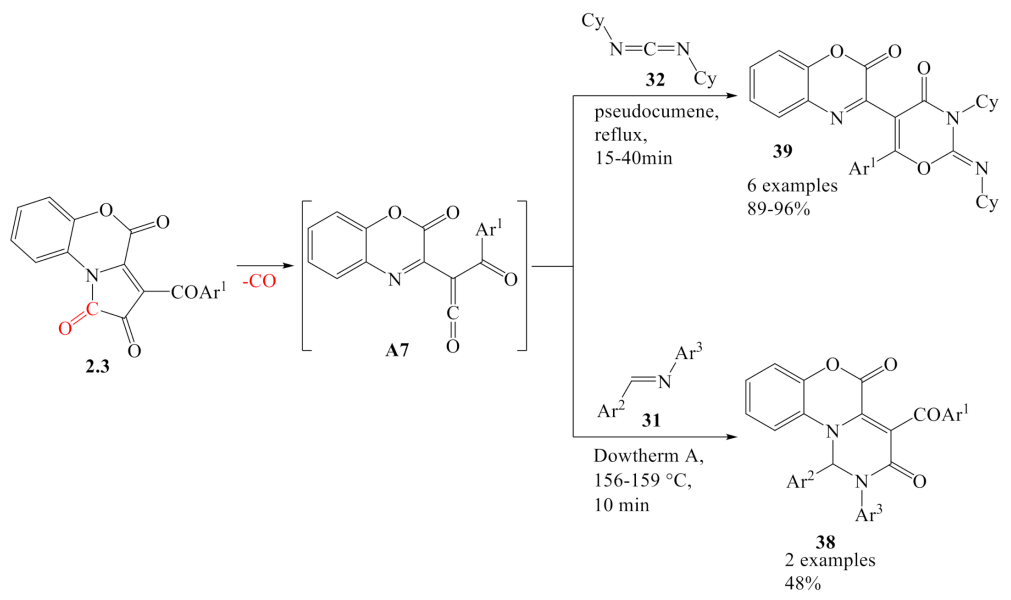

Scheme 26. Interception of acyl(imidoyl)ketenes A7 by Schiff bases $\mathbf{3 1}$ and carbodiimides 32 with formation of 1,2-dihydrobenzo[b]pyrimido[1,6- $d][1,4]$ oxazine-3,5-diones 38 or 3-(2-imino-4-oxo-3,4dihydro-2H-1,3-oxazin-5-yl)-2H-benzo[b][1,4] oxazin-2-ones 39, respectively.

\subsubsection{Interception Reactions of Acyl(imidoyl)ketenes with Water}

As acyl(imidoyl)ketenes $\mathbf{A}$ are highly reactive compounds, they can react with air moisture and moisture from reaction vessels which are not thoroughly dried, solvents, and reagents $[54,67]$. In these cases, reaction mixtures contain various side products formed as a result of hydrolysis of acyl(imidoyl)ketenes $\mathbf{A}$. 
Thus, zwitterions D2, formed as a result of intramolecular cyclization of methyleneamino substituted acyl(imidoyl)ketenes A9, react with water to afford pyrazolones $\mathbf{4 0}$ (Scheme 27) [67]. This process is accompanied by formation of benzophenone $\mathrm{Ph}_{2} \mathrm{CO}$.

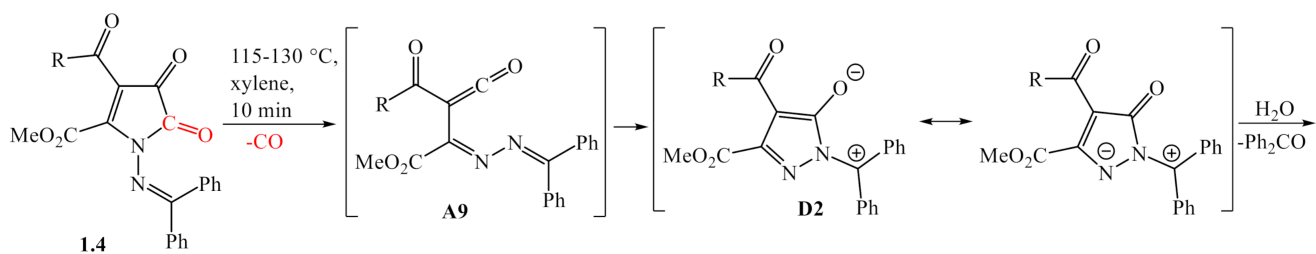<smiles></smiles>

Scheme 27. Interception of zwitterions D2, formed from methyleneamino substituted acyl(imidoyl)ketenes A9, by water with formation of pyrazolones $\mathbf{4 0 .}$

$N^{4}$-Phenyl substituted acyl(quinoxalin-2-yl)ketenes A6 generated from $N^{5}$-phenyl substituted 3-acylpyrroloquinoxalinetriones $\mathbf{2 . 2}$ react with water to result in corresponding enamines 41 (Scheme 28) [54]. The same hydrolysis pathway is likely typical for other similar ketenes A6-A8, generated from [e]-fused 1H-pyrrole-2,3-diones 2 or furan-2,3diones 3.

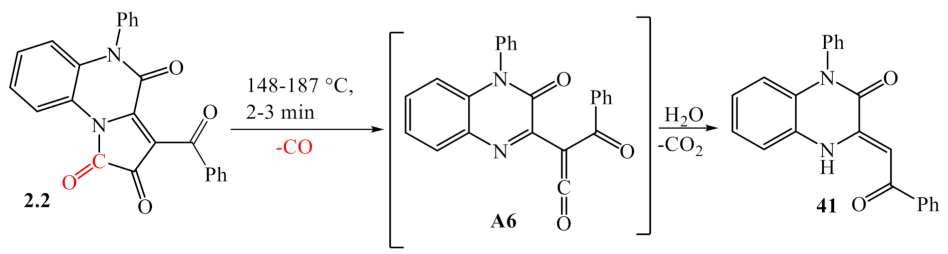

Scheme 28. Hydrolysis of acyl(imidoyl)ketenes A6 with formation of enamines 41.

\section{Conclusions}

There are many examples of various thermolytic reactions in a solvent medium or gas phase (FVT), enabling the generation of highly reactive compounds with symmetric but unequal reaction centers $(\mathrm{C}=\mathrm{C}-\mathrm{C}=\mathrm{O}$ and $\mathrm{C}=\mathrm{C}-\mathrm{C}=\mathrm{N})$, acyl(imidoyl)ketenes, the immediate transformation of which can proceed in two patterns, intramolecular cyclization reactions, and intermolecular ones. Immediate reactions of these compounds can afford synthesis of many various heterocycles, which is a desired property for DOS of small molecule libraries for drug discovery.

This review shows that the pattern of immediate transformation of an acyl(imidoyl) ketene dramatically depends on the structure of the substituent at nitrogen atom in imidoyl $\mathrm{C}=\mathrm{N}$ moiety.

Acyl(imidoyl)ketenes bearing a conformationally free substituents at nitrogen atom in imidoyl $\mathrm{C}=\mathrm{N}$ moiety are prone to intramolecular cyclizations. At the same time, incorporation in this position of a methyleneamino substituent affords intramolecular cyclization of such ketenes to tautomeric zwitterions that can undergo intermolecular reactions.

Acyl(imidoyl)ketenes bearing a conformationally rigid substituent at nitrogen atom in imidoyl $\mathrm{C}=\mathrm{N}$ moiety are prone to intermolecular reactions. In such reactions, in dependence on the structure of trapping reagents, such acyl(imidoyl)ketenes can react as oxa-dienes, aza-dienes, and dienophiles.

Thus, this review indicates that a relatively small amount of different types of substituents were installed into molecules of acyl(imidoyl)ketenes. However, even this small 
amount of substituent variants gave rise to a large number of diverse products. These make acyl(imidoyl)ketenes a promising class of chemical compounds for the development of small molecule libraries, and intriguing objects for investigations of properties of highly reactive chemical species.

Author Contributions: Writing—original draft preparation, E.A.L. and E.E.K.; writing-review and editing, E.E.K.; supervision, A.N.M. and E.E.K. All authors have read and agreed to the published version of the manuscript.

Funding: This research was funded by the Russian Science Foundation, grant number 19-13-00290.

Institutional Review Board Statement: Not applicable.

Informed Consent Statement: Not applicable.

Conflicts of Interest: The authors declare no conflict of interest.

\section{References}

1. Burke, M.; Schreiber, S. A Planning Strategy for Diversity-Oriented Synthesis. Angew. Chem. Int. Ed. 2004, 43, 46-58. [CrossRef]

2. Collins, S.; Bartlett, S.; Nie, F.; Sore, H.F.; Spring, D.R. Diversity-oriented synthesis of macrocycle libraries for drug discovery and chemical biology. Synthesis 2016, 48, 1457-1473. [CrossRef]

3. Schneider, G. Automating drug discovery. Nat. Rev. Drug Discov. 2018, 17, 97-113. [CrossRef] [PubMed]

4. Pavlinov, I.; Gerlacha, E.M.; Aldrich, L.N. Next generation diversity-oriented synthesis: A paradigm shift from chemical diversity to biological diversity. Org. Biomol. Chem. 2019, 17, 1608-1623. [CrossRef] [PubMed]

5. Dandapani, S.; Marcaurelle, L.A. Current strategies for diversity-oriented synthesis. Curr. Opin. Chem. Biol. 2010, 14, 362-370. [CrossRef] [PubMed]

6. Yi, S.; Varun, B.V.; Choi, Y.; Park, S.B. A Brief Overview of Two Major Strategies in Diversity-Oriented Synthesis: Build/Couple/Pair and Ring-Distortion. Front. Chem. 2018, 6, 507. [CrossRef]

7. Kidd, S.L.; Osberger, T.J.; Mateu, N.; Sore, H.F.; Spring, D.R. Recent Applications of Diversity-Oriented Synthesis Toward Novel, 3-Dimensional Fragment Collections. Front. Chem. 2018, 6, 460. [CrossRef]

8. Jiang, X.; Hao, X.; Jing, L.; Wu, G.; Kang, D.; Liu, X.; Zhan, P. Recent applications of click chemistry in drug discovery. Expert Opin. Drug. Discov. 2019, 4, 779-789. [CrossRef]

9. Gerry, C.J.; Schreiber, S.L. Recent achievements and current trajectories of diversity-oriented synthesis. Curr. Opin. Chem. Biol. 2020, 56, 1-9. [CrossRef]

10. Greer, A.; Wauchope, O.R.; Farina, N.S.; Haberfield, P.; Liebman, J.F. Paradigms and paradoxes: Mechanisms for possible enhanced biological activity of bilaterally symmetrical chemicals. Struct. Chem. 2006, 17, 347-350. [CrossRef]

11. Bai, W.-J.; Wang, X. Appreciation of symmetry in natural product synthesis. Nat. Prod. Rep. 2017, 34, 1345-1358. [CrossRef] [PubMed]

12. Bellus, D.; Aizpurua, J.M.; Kowalczyk, J.J.; Austin, W.F.; Moore, H.W.; Danheiser, R.L.; Oiarbide, M.; Dudley, G.B.; Palomo, C.; Ebner, S.; et al. Science of Synthesis, 23: Category 3, Compounds with Four and Three Carbon Heteroatom Bonds, 1st ed.; Edition Thieme Verlagsgrouppe: Stuttgart, Germany; New York, NY, USA; Rio, Brazil, 2006. [CrossRef]

13. Tidwell, T.T. Ketenes, 2nd ed.; Wiley-Interscience: Hoboken, NJ, USA, 2006. [CrossRef]

14. Fulloon, B.E.; Wentrup, C. Fluoroquinolones from Imidoylketenes and Iminopropadienones, $\mathrm{R}-\mathrm{N}=\mathrm{C}=\mathrm{C}=\mathrm{C}=\mathrm{O}$. Aust. J. Chem. 2009, 62, 115-120. [CrossRef]

15. McNab, H.; Hill, L.; Imam, S.; O'Neill, W. Regioselective Synthesis of Quinolin-4-ones by Pyrolysis of Anilinomethylene Derivatives of Meldrum's Acid. Synlett 2009, 2009, 1847-1851. [CrossRef]

16. Presset, M.; Coquerel, Y.; Rodriguez, J. Microwave-assisted domino and multicomponent reactions with cyclic acylketenes: Expeditious syntheses of oxazinones and oxazindiones. Org. Lett. 2009, 11, 5706-5709. [CrossRef]

17. Reber, K.P.; Tilley, S.D.; Sorensen, E.J. Bond formations by intermolecular and intramolecular trappings of acylketenes and their applications in natural product synthesis. Chem. Soc. Rev. 2009, 38, 3022-3034. [CrossRef]

18. Alajarin, M.; Bonillo, B.; Sanchez-Andrada, P.; Vidal, A. Tandem 1,5-hydride shift/1,5-S,N-cyclization with ethylene extrusion of 1,3-oxathiolane-substituted ketenimines and carbodiimides. An experimental and computational study. J. Org. Chem. 2010, 75, 3737-3750. [CrossRef]

19. Gaywood, A.P.; Hill, L.; Imam, S.H.; McNab, H.; Neumajer, G.; O’Neill, W.J.; Matyus, P. Cyclisation reactions of some pyridazinylimidoylketenes. New J. Chem. 2010, 34, 236-242. [CrossRef]

20. Presset, M.; Coquerel, Y.; Rodriguez, J. Periselectivity switch of acylketenes in cycloadditions with 1-azadienes: Microwaveassisted diastereoselective domino three-component Synthesis of $\alpha$-spiro- $\delta$-lactams. Org. Lett. 2010, 12, 4212-4215. [CrossRef]

21. Leber, S.; Kollenz, G.; Wentrup, C. Synthesis of functionalized macrocyclic derivatives of trioxabicyclo[3.3.0]nonadiene. Beilstein J. Org. Chem. 2012, 8, 738-743. [CrossRef]

22. Nunes, C.M.; Reva, I.; Pinho e Melo, T.M.V.D.; Fausto, R. UV-Laser photochemistry of isoxazole isolated in a low-temperature matrix. J. Org. Chem. 2012, 77, 8723-8732. [CrossRef] 
23. Galvez, J.; Castillo, J.-C.; Quiroga, J.; Rajzmann, M.; Rodriguez, J.; Coquerel, Y. Divergent chemo-, regio-, and diastereoselective normal electrondemand povarov-type reactions with $\alpha$-oxo-ketene dienophiles. Org. Lett. 2014, 16, 4126-4129. [CrossRef]

24. Khlebnikov, A.F.; Novikov, M.S.; Pakalnis, V.V.; Iakovenko, R.O.; Yufit, D.S. Domino reactions of $2 H$-azirines with acylketenes from furan-2,3-diones: Competition between the formation of ortho-fused and bridged heterocyclic systems. Beilstein J. Org. Chem. 2014, 10, 784-793. [CrossRef]

25. Zavyalov, K.V.; Novikov, M.S.; Khlebnikov, A.F.; Pakalnis, V.V. Selective syntheses of 2H-1,3-oxazines and $1 H$-pyrrol-3(2H)-ones via temperature-dependent $\mathrm{Rh}$ (II)-carbenoid-mediated $2 \mathrm{H}$-azirinering expansion. Tetrahedron 2014, 70, 3377-3384. [CrossRef]

26. Cookson, R.; Barrett, T.N.; Barrett, A.G.M. $\beta$-Keto-dioxinones and $\beta, \delta$-diketo-dioxinones in biomimetic resorcylate total synthesis. Acc. Chem. Res. 2015, 48, 628-642. [CrossRef] [PubMed]

27. Miyamaru, S.; Umezu, K.; Ito, A.; Shimizu, M. Synthesis of multisubstituted dihydroquinoxaline derivatives by tandem Nalkylation and addition reactions of 3-oxoquinoxaline-2-carboxylates. Eur. J. Org. Chem. 2015, 2015, 3327-3337. [CrossRef]

28. Rezvanian, A. An expedient synthesis strategy to the 1,4-dihydropyridines and pyrido[1,2-a]quinoxalines: Iodine catalyzed one-pot four-component domino reactions. Tetrahedron 2016, 72, 6428-6435. [CrossRef]

29. Azev, Y.A.; Kodess, M.I.; Ezhikova, M.A.; Ermakova, O.S.; Berseneva, V.S.; Bakulev, V.A. Reactions of quinoxalin-2-one with $\beta$-diketones: A new approach to 6a,7-dihydro-5H-pyrido[1,2-a]quinoxaline-6,8-diones. Mendeleev Commun. 2017, 27, 97-98. [CrossRef]

30. Azev, Y.A.; Ermakova, O.S.; Berseneva, V.S.; Kodess, M.I.; Ezhikova, M.A.; Ganebnykh, I.N. Synthesis of the 6-oxidopyrido[1,2a]quinoxalinium derivatives from quinoxalin-2-one and aldehydes-New examples of domino reactions. Mendeleev Commun. 2017, 27, 637-639. [CrossRef]

31. Hu, Z.; Dong, J.; Men, Y.; Lin, Z.; Cai, J.; Xu, X. Silver-catalyzed chemoselective [4+2] annulation of two isocyanides: A general route to pyridone-fused carbo- and heterocycles. Angew. Chem. Int. Ed. 2017, 56, 1805-1809. [CrossRef]

32. Kollenz, G.; Wentrup, C. From dipivaloylketene to tetraoxaadamantanes. Beilstein J. Org. Chem. 2018, 14, 1-10. [CrossRef]

33. Soozani, A.; Keivanloo, A.; Bakherad, M. One-pot palladium-catalyzed synthesis of functionalized 10H-pyrido[1,2-a]quinoxalin10-ones under copper-free conditions. Tetrahedron 2018, 74, 150-156. [CrossRef]

34. Galaverna, R.; McBride, T.; Pastre, J.C.; Browne, D.L. Exploring the generation and use of acylketenes with continuous flow processes. React. Chem. Eng. 2019, 9, 1559-1564. [CrossRef]

35. Luo, J.; Chen, G.-S.; Chen, S.-J.; Liu, Y.-L. Catalyst-free formal [4+1]/[4+2] cyclization cascade sequence of isocyanides with two molecules of acylketene formed in situ from thermal-induced Wolff rearrangement of 2-diazo-1,3-diketones. Sci. Bull. 2020, 65, 670-677. [CrossRef]

36. Kollenz, G.; Igel, H.; Ziegler, E. Uber reaktionen mit cyclischen oxalylverbindungen, 6. mitt.: Synthesen von heterocyclen, 161. Mitt. Monatsh. Chem. 1972, 103, 450-459. [CrossRef]

37. Briehl, H.; Lukosch, A.; Wentrup, C. Reactive nitrogenous molecules from Meldrum's acid derivatives, pyrrole-2,3-diones, and isoxazolones. J. Org. Chem. 1984, 49, 2772-2779. [CrossRef]

38. Sano, T. Syntheses of heterocyclic compounds containing nitrogen utilizing dioxopyrrolines. J. Syn. Org. Chem. JPN 1984, 42 , 340-354. [CrossRef]

39. Kappe, C.O.; Kollenz, G.; Wentrup, C. A Nitroketene to Nitrile Oxide Transformation. J. Chem. Soc. Chem. Commun. 1992, 485-486. [CrossRef]

40. George, L.; Netsch, K.-P.; Penn, G.; Kollenz, G.; Wentrup, C. Oxoketene-oxoketene, imidoylketene-imidoylketene and oxoketenimine-imidoylketene rearrangements. 1,3-Shifts of phenyl groups. Org. Biomol. Chem. 2006, 4, 558-564. [CrossRef]

41. Vasvari-Debreczy, L.; Hermecz, I.; Meszaros, Z.; Dvortsak, P.; Toth, G. Nitrogen bridgehead compounds. Part 6. Ring transformation. Part 3. Thermal cyclization of diethyl 2-(2-pyridylaminomethylene)-succinates and -glutarates. J. Chem. Soc. Perkin Trans. 1980, 1, 227-232. [CrossRef]

42. Wernik, M.; Hartmann, P.E.; Sipos, G.; Darvas, F.; Boese, A.D.; Dallinger, D.; Kappe, C.O. On the Regioselectivity of the Gould-Jacobs reaction: Gasphase versus solution-phase thermolysis. Eur. J. Org. Chem. 2020, 2020, 7051-7061. [CrossRef]

43. Kappe, C.O.; Kollenz, G.; Leung-Toung, R.; Wentrup, C. Methyleneketene-lmidoylketene-oxoketenimine rearrangements. J. Chem. Soc. Chem. Commun. 1992, 487-488. [CrossRef]

44. Kappe, C.O.; Kollenz, G.; Netsch, K.-P.; Leung-Toung, R.; Wentrup, C. Imidoylketene-azetin-2-one-oxoketenimine rearrangement. J. Chem. Soc. Chem. Commun. 1992, 488-490. [CrossRef]

45. Tsuda, Y.; Horiguchi, Y.; Sano, T. Diels-Alder reaction in a polar system. Thermal cycloaddition of 1-phenyl-2-ethoxycarbonyl-3benzoyl- $\Delta^{2}$-pyrroline-4,5-dione with butadienes. Heterocycles 1976, 4, 1355-1360. [CrossRef]

46. Maslivets, A.N.; Krasnykh, O.P.; Smirnova, L.I.; Andreichikov, Y.S. Five-membered dioxoheterocycles. XII. Thermolysis of 1-aryl-4-aroyl-5-methoxycarbonyl-2,3-dihydro-2,3-pyrrolediones. J. Org. Chem. USSR 1989, 25, 941-948. (In Russian)

47. Abd EI-Nabi, H.A.; Kollenz, G. Reactions of cyclic oxalyl compounds XXXIX. Reactions of 4-ethoxycarbonyl-5-phenyl-2,3dihydrofuran-2,3-dione with heterocumulenes and Schiff bases. Monatsh. Chem. 1997, 128, 381-387. [CrossRef]

48. Silaichev, P.S.; Kudrevatykh, N.V.; Maslivets, A.N. Five-membered 2,3-dioxoheterocycles: LXXXIII. Synthesis and thermolysis of 1-aryl-4,5-diaroyl-1H-pyrrole-2,3-diones. Russ. J. Org. Chem. 2012, 48, 249-252. [CrossRef]

49. Boteva, A.A.; Krasnykh, O.P.; Fefilova, I.V.; Babushkina, E.B.; Slepukhin, P.A. Methyl 3-aroyl-4-oxo-1,4-dihydroquinoline-2carboxylates: Synthesis and molecular and crystal structures. Russ. Chem. Bull. 2014, 63, 731-738. [CrossRef] 
50. Saripinar, E.; Karatas, S. Synthesis and thermolysis of the 2,3-dihydro-1H-pyrole-2,3-diones, pseudopericyclic reactions of formyl( $N$-phenylimidoyl)ketene: Experimental data and PM3 calculations. J. Heterocycl. Chem. 2005, 42, 787-796. [CrossRef]

51. Aliev, Z.G.; Krasnykh, O.P.; Maslivets, A.N.; Stepanov, O.S.; Andreichikov, Y.S.; Atovmyan, L.O. Chemistry of acyl(imidoyl)ketenes. 4. Synthesis and crystal and molecular structure of 3-benzoyl-4-benzylamino-5-phenyl-5H-furan-2-one. Russ. Chem. Bull. 1999, 48, 2127-2130. [CrossRef]

52. Aliev, Z.G.; Maslivets, A.N.; Golovnina, O.V.; Krasnykh, O.P.; Atovmyan, L.O. Chemistry of acyl(imidoyl)ketenes. 6. Synthesis and the molecular structure of ethyl 2-oxo-2,5-dihydrofuro[2,3-b]quinoxaline-3-carboxylate. Russ. Chem. Bull. 2001, 50, 1317-1319. [CrossRef]

53. Mashevskaya, I.V.; Mokrushin, I.G.; Bozdyreva, K.S.; Maslivets, A.N. Five-membered 2,3-dioxoheterocycles: LXXIII. Synthesis and thermolysis of 3-acylpyrrolo[1,2-a]quinoxaline-1,2,4(5H)-triones. Russ. J. Org. Chem. 2011, 47, 253-257. [CrossRef]

54. Kasatkina, S.O.; Stepanova, E.E.; Maslivets, A.N. Synthesis of pyrimido[1,6- $a$ ]quinoxalines via intermolecular trapping of thermally generated acyl(quinoxalin-2-yl)ketenes by Schiff bases. Beilstein J. Org. Chem. 2018, 14, 1734-1742. [CrossRef]

55. Lisowskaya, N.A.; Alajarin, M.; Sanchez-Andrada, P. New cyclization mode of [ $N$-(diarylmethyleneamino)carbonimidoyl]ketenes: Synthesis of $9 H$-pyrazolo[3,2-b][1,3]benzoxazines. Eur. J. Org. Chem. 2006, 2006, 1468-1475. [CrossRef]

56. Maslivets, A.N.; Aliev, Z.G.; Krasnykh, O.P.; Golovnina, O.V.; Atovmyan, L.O. Chemistry of acyl(imidoyl)ketenes. 8. Thermolysis of 3-Alkoxycarbonyl-5-phenyl-1,2,4,5-tetrahydropyrrolo[1,2-a]quinoxaline-1,2,4-triones. Structure of 2-(3-oxo-4-phenyl-3,4dihydro-2-quinoxalinyl)-2,4-di(ethoxycarbonyl)-6-phenyl-2,3,5,6-tetrahydro-1H-pyrido[1,2-a]quinoxaline-1,3,5-trione. Chem. Heterocycl. Compd. 2004, 40, 1295-1299. [CrossRef]

57. Silaichev, P.S.; Maslivets, A.N. Two methods for generation of aroyl(quinoxalin-2-yl)ketene. Russ. J. Org. Chem. 2012, 48, 1261-1262. [CrossRef]

58. Lisovenko, N.Y.; Krasnykh, O.P.; Aliev, Z.G.; Vostrov, E.S.; Tarasova, O.P.; Maslivets, A.N. Intermolecular cyclodimerization of aroyl(imidoyl)ketenes generated by thermolysis of 5-aryl-4-imidoyl2,3-dihydro-2,3-furandiones. Chem. Heterocycl. Compd. 2001, 37, 1314-1316. [CrossRef]

59. Maslivets, A.N.; Lisovenko, N.Y.; Krasnykh, O.P.; Tarasova, O.P.; Aliev, Z.G.; Atovmyan, L.O. Chemistry of acyl(imidoyl)ketenes. 7. Synthesis and thermolysis of 5-aryl-4-quinoxalinyl-2,3-dihydrofuran-2,3-diones. Russ. Chem. Bull. 2002, 51, 850-853. [CrossRef]

60. Lisovenko, N.Y.; Yukova, Y.V.; Makhmudov, R.R. Synthesis and analgesic activity of substituted pyridoquinoxalinyl arylates and their hydrolysis products. Pharm. Chem. J. 2014, 47, 593-595. [CrossRef]

61. Maslivets, V.A.; Maslivets, A.N. Five-membered 2,3-dioxo heterocycles: LXXXVIII. Reaction of 3-aroylpyrrolo[1,2d][1,4] benzoxazine-1,2,4(4H)-triones with $N, N^{\prime}$-dicyclohexylcarbodiimide under thermolysis conditions. Russ. J. Org. Chem. 2012, 48, 1233-1237. [CrossRef]

62. Bozdyreva, K.S.; Smirnova, I.V.; Maslivets, A.N. Five-membered 2,3-dioxo heterocycles: L. Synthesis and thermolysis of 3aroyl- and 3-hetaroyl-5-phenyl-1,2,4,5-tetrahydropyrrolo[1,2-a]quinoxalin-1,2,4-triones. Russ. J. Org. Chem. 2005, 41, 1081-1088. [CrossRef]

63. Semenova, T.D.; Krasnykh, O.P. Chemistry of acyl(imidoyl)ketenes: IX. Synthesis and thermolysis of 3-aroyl-8-chloro-1,2-dihydro4H-pyrrolo[2,1-c][1,4]benzoxazine-1,2,4-triones. Russ. J. Org. Chem. 2005, 41, 1222-1227. [CrossRef]

64. Zhulanov, V.E.; Dmitriev, M.V.; Maslivets, A.N.; Rubin, M. New method for in-situ generation of enolate-iminium 1,4-dipoles for [4+2] and [4+1] dipolar heterocycloaddition reactions. RSC Adv. 2016, 6, 90239-90247. [CrossRef]

65. Zhulanov, V.E.; Vigovskaya, V.A.; Dmitriev, M.V.; Silaichev, P.S.; Maslivets, A.N.; Rubin, M. Dipyrazolodioxadiazocines as shelfstable "ready-to-use" precursors for an in situ generation of enolate-iminium 1,4-dipoles: A straightforward atom-economical approach to pyrazolo[5,1-d][1,3,5]dioxazines. Org. Biomol. Chem. 2020, 18, 3382-3391. [CrossRef] [PubMed]

66. Kollenz, G. Zur Fischer-indol-umlagerung sterisch gehinderter systeme, 6. Mitt.: Reaktionen mit cyclischen oxalylverbindungen, 22. Mitt. Monatsh. Chem. 1978, 109, 249-257. [CrossRef]

67. Zhulanov, V.E.; Dmitriev, M.V.; Maslivets, A.N. Thermolysis of 1-(methylideneamino)-1H-pyrrole-2,3-diones. Synthesis of pyrazolooxazines by [4+2]-cycloaddition of azomethine imines to alkenes. Russ. J. Org. Chem. 2017, 53, 1531-1536. [CrossRef]

68. Nekrasov, D.D.; Obukhova, A.S.; Lisovenko, N.Y.; Roubtsov, A.E. Effect of substituents in the cumulene and aryl fragments of aroylketenes on the stereoselectivity of Diels-Alder heteroreaction with mono-, bi-, and polycyclic terpenoids containing a carbonyl group. Chem. Heterocycl. Compd. 2010, 46, 413-418. [CrossRef]

69. Lisovenko, N.Y.; Maslivets, A.N.; Aliev, Z.G. Five-membered 2,3-dioxo heterocycles: XLVI. Reaction of 5-aryl-4-quinoxalinyl-2,3dihydrofuran-2,3-diones with aldehydes and ketones. Molecular and crystalline structure of 5-(3-p-tolylquinoxalin-2-yl)-4H-1,3dioxine-2-spiro-2'-adamantan-4-one. Russ. J. Org. Chem. 2004, 40, 1053-1057. [CrossRef]

70. Kasatkina, S.; Stepanova, E.; Dmitriev, M.; Mokrushin, I.; Maslivets, A. Divergent synthesis of (quinoxalin-2-yl)-1,3-oxazines and pyrimido[1,6-a]quinoxalines via the cycloaddition reaction of acyl(quinoxalinyl)ketenes. Tetrahedron Lett. 2019, 60, 151088. [CrossRef]

71. Maslivets, V.A.; Maslivets, A.N. Two pathways in the cycloaddition of 4-nitrobenzaldehyde to acyl(imidoyl)ketene. Russ. J. Org. Chem. 2013, 49, 1092-1093. [CrossRef]

72. Lisovenko, N.Y.; Nekrasov, D.D.; Karmanov, V.I. Thermolytic transformations of 5-aryl-4-quinoxalin-2-ylfuran-2,3-diones in the presence of $\mathrm{N}$-cyano compounds. Chem. Heterocycl. Compd. 2012, 48, 1357-1360. [CrossRef] 
73. Lisovenko, N.Y.; Maslivets, A.N.; Aliev, Z.G. Five-membered 2,3-dioxo heterocycles: LII. Reactions of 5-aryl-4-(quinoxalin-2-yl)2,3-dihydrofuran-2,3-diones with Schiff bases and dicyclohexylcarbodiimide. Crystalline and molecular structure of substituted 2-(4-oxo-3,4-dihydro-2H-1,3-oxazin-5-yl)quinoxalines. Russ. J. Org. Chem. 2007, 43, 117-120. [CrossRef]

74. Aliev, Z.G.; Krasnykh, O.P.; Maslivets, A.N.; Andreichikov, Y.S.; Atovmyan, L.O. Chemistry of acyl(imidoyl)ketenes. 3. Synthesis and structure of l-p-bromophenyl-2-p-methoxyphenyl-4-p-toluoyl-1,2-dihydropyrimidino[4,3-c][1,4]benzoxazine-3,5-dione. Russ Chem. Bull. 1999, 48, 608-611. [CrossRef] 